\title{
A Novel Semi-Visualizable Experimental Study of a Plate Gravity Heat Pipe at Unsteady State
}

\author{
Xiang Gou * (D), Yamei Li, Qiyan Zhang, Imran Ali Shah (D), Dong Zhao, Shian Liu, Yating Wang, \\ Enyu Wang and Jinxiang Wu \\ School of Energy and Environmental Engineering, Hebei University of Technology, 5340\# Xiping Road, \\ Shuangkou Town, Beichen District, Tianjin 300401, China; lymlyh910901@126.com (Y.L.); \\ zhangqiyan0810@sina.com (Q.Z.); coaltechnology@gmail.com (I.A.S.); zd786457517@163.com (D.Z.); \\ lsa0810@163.com (S.L.); wyt6816@163.com (Y.W.); enyuwang@163.com (E.W.); wujnxd@163.com (J.W.) \\ * Correspondence: gouxiang@sina.com or xgou@hebut.edu.cn; Tel.: +86-22-6043-5781
}

Received: 3 November 2017; Accepted: 26 November 2017; Published: 1 December 2017

\begin{abstract}
An experimental study on a plate gravity heat pipe (PGHP) with inner cavity size of length $100 \mathrm{~mm}(\mathrm{X})$, width $2.5 \mathrm{~mm}(\mathrm{Y})$, and height $210 \mathrm{~mm}(\mathrm{Z})$ with acetone as the working fluid was carried out. The effects of heating power inputs ( $80-180 \mathrm{~W})$ and fluid filling ratios $(25 \%, 48 \%$, and $55 \%)$ on the start-up temperature, start-up time, temperature difference, and relative thermal resistance on the Z-axis of the PGHP in a vacuum of $1 \times 10^{-3}$ Pa were studied at unsteady state. Furthermore, the gas-liquid two-phase behavior of the interior working fluid of PGHP, and the coupling heat transfer behavior of the boiling liquid and the condensate were observed through a visualizable window under different experimental conditions. The results show that, with the increase of heating power input, the start-up temperature of the PGHP increases and the start-up time is shortened. The start-up temperature of the PGHP was around $33^{\circ} \mathrm{C}$ and the start-up time was about $320 \mathrm{~s}$ at the heating power input of $120 \mathrm{~W}$ and working fluid filling ratio of $55 \%$. The relative thermal resistance and the temperature difference on the Z-axis of the PGHP increase firstly and then decrease with the increase of heating power input at unsteady state. The complex gas-liquid two-phase behavior of the PGHP mainly includes: the formation and growth of bubbles, the merging and break up of bubbles, and the coupling heat transfer between boiling liquid and condensate, which demonstrate that the novel SVPGHP can be used to effectively study the heat transfer process of PGHP.
\end{abstract}

Keywords: plate gravity heat pipe (PGHP); semi-visualization; phase change heat transfer; flow characteristics

\section{Introduction}

Due to the advantages of small volume, high heat transfer efficiency, compact structure, low pressure drop and no auxiliary power of the heat pipe [1-6], the plate heat pipe (PHP) is widely used as a highly efficient heat transfer element in various industries. It has a phase change device with high heat transfer efficiency and meets the requirements of heat transfer for high-power chips [7-9]. The PHP includes horizontal plate heat pipe (HPHP) and vertical plate heat pipe (VPHP). VPHP is also called plate gravity heat pipe (PGHP). Due to its complex flow and heat transfer mechanism, many scholars have made lots of theoretical research and numerical analyses of the PHP. These researches focus on the heat transfer mechanism, the heat transfer limit, and the heat transfer factors that affect the heat transfer characteristics.

The effects of different heat fluxes and inclination angles on heat transfer resistance of PHP were analyzed through experimental study [10] and numerical simulation [11]. The results showed that the smaller effective thermal conductivity of the wick could produce a larger temperature gradient, especially in the heating region near the heat source. Hansen et al. [12] conducted an experiment to analyze the application of PGHP for heat transfer from a unilateral heat source, with special 
emphasis on the performance of the wick. In that heat pipe, a wick of compressed nickel foam covered only the evaporator surface using potassium as the working fluid. Thermal deformation due to unilateral heat flux was analyzed by the use of COMSOL Multiphysics ${ }^{\circledR}$. The results revealed that a vertical rectangular wick was shown to be most vulnerable to hot spots at the upper corners. Kim et al. [13] obtained the heat transfer performance of the three-phase flow PHP and the two-phase flow PHP by experiment, using acetone as the working fluid. $\mathrm{Al}_{2} \mathrm{O}_{3}$ nanoparticles were added into the three-phase flow PHP to study the effect of nanoparticle shape on heat transfer performance of PHP. The results showed that the thermal resistances of the PHP with nanofluids containing sphere-, brickand cylinder-shaped nanoparticles were reduced to $33 \%, 29 \%$, and $16 \%$, respectively. Hari et al. [14] used a multiphase flow model to simulate the process of evaporation and condensation in the capillary core of the PHP, and analyzed the flow characteristics of the working fluid. Chen and Chou [3] studied the effects of the length and inclination angle of the PHP on the heat transfer in the condensation section. The thermal resistance, the maximum heat transfer and the thermal conductivity were used as the standard, and the effect of structure on heat transfer of PHP was obtained through experiment. Huang et al. [15] presented a design method to fabricate a novel hybrid-structure flat plate heat pipe (NHSP heat pipe) for a photovoltaic concentrator. The NHSP heat pipe was composed of a flattened copper pipe and a sintered wick structure, and a coronary-stent-like rhombic copper mesh supports the structure. The results showed that the NHSP heat pipe provided the best performance for the photovoltaic concentrator, which could increase photoelectric conversion efficiency by approximately $3.1 \%$, compared to an aluminum substrate. Peng et al. [16] performed an experimental study on the heat transfer performance of a novel plate aluminum heat pipe. The effects of airflow rates, fluid filling ratios, vacuum degrees and working fluids on the heat transfer characteristics of the new type plate aluminum heat pipe were analyzed. Tan et al. [17] introduced an analytical method to predict the distribution of internal velocity and pressure in the plate heat pipe at different heat sources, and obtained the optimum position of the heat source heating of the PHP. Ji et al. [18] designed a new type of integrated heat pipe, which mainly included an evaporator and a condenser. The condenser was composed of a number of rectangular heat dissipation passages, and there was an experimental study on the integrated heat pipe radiator. The results showed that compared with the traditional plate heat pipe, the integrated heat pipe had better temperature uniformity and heat transfer characteristics. Hansen et al. [19] investigated the fabrication and performance of wicks for PHP applications produced by sintering a filamentary nickel powder. The influence on wick performance by using pore former in the manufacturing process was studied. The results showed that when $P_{\text {cap }} / P_{\text {sat }}>1$, the use of a pore former to increase the wick permeability will always improve the wick performance. While $P_{\text {cap }} / P_{\text {sat }}<1$, it was shown that if the effective pore radius and the permeability increase with an equal percentage the overall influence on the wick capacity is negative.

Meanwhile, the pool boiling phenomenon of a large container is similar to the boiling phenomenon of the working fluid inside the heat pipe. Halon et al. [20] studied the process of bubble creation and detachment, the bubble departure diameters and the frequencies for three different narrow tunnel structures (NTS) in pool boiling of water at sub-atmospheric pressure. The results showed that the NTS structures integrated with perforated copper foil substantially increased the heat transfer coefficient and the bubble departure frequency. At sub-atmospheric pressure, bubble departure diameter increases. Bubble departure frequency is significantly influenced by different NTS structures. Michaie et al. [21] conducted experiments of water pool boiling at saturation state from atmospheric pressure down to $4.2 \mathrm{KPa}$ with a single imposed heat flux at the heater. In order to analyze the bubble dynamics for different pressures, videos of each experiment were recorded with a high-speed camera. It was found that the size and detachment frequency of bubbles increased with the decreases of pressure, while the bubble shape changed from a near-spherical shape at atmospheric pressure to an oblate spheroidal shape at the lowest investigated pressure. Deng et al. [22] experimented with water and ethanol at atmospheric pressure. The surface under test was a copper specimen with micro-channels in cross-section. Visualization studies revealed nucleation, growth and departure behaviors in the cavities and also that at higher heat fluxes, 
the bubbles tend to merge. Kaniowski and Pastuszko [23] presented visualization investigations into pool boiling heat transfer for open mini-channel surfaces. The visualization study was used to identify nucleation sites of the departing bubbles and to determine their diameters and frequency at various superheats. The results showed that the bubbles between the heated surface and liquid were spherical in shape and did not merge at low superheat. However, the bubbles interacted with each other intensively, forming flattened spherical shapes funnel-shaped at the bottom under higher superheats. At the same time, Falcucci et al. used the Lattice Boltzmann Method to study cavitating flows in the nozzle [24], stress-induced cavitation [25], flow-induced cavitation in orifices [26], and phase-separating flows at large density ratios [27]. De Rosis et al. presented a coupled lattice Boltzmann-finite element approach for two-dimensional fluid-structure interaction [28], which had been used to study the hydroelastic analysis of hull slamming [29]. These methods lay the foundation for the numerical simulation of multiphase flow in heat pipe.

In addition, in order to be more intuitive to observe the change of the working fluid in the PHP, many scholars designed visual experimental apparatus for experimental studies [30-37]. And most of visualization researches were mainly concentrated on the pulsating heat pipe, the closed loop heat pipe (LHP), and the silicon-based micro pulsating heat pipes (MPHP).

Most of the above experiments focus on HPHP, but less on PGHP. The study of PGHP will be mentioned when the influence of inclination angle on horizontal plate heat pipe is discussed $[3,10,11]$. In order to do more comprehensive study of PGHP and further understand the heat transfer mechanism of PGHP, a semi-visualized plate gravity heat pipe (SVPGHP) was designed and manufactured in this study. Two reasons are considered for using a semi-visualizable window. Firstly, the experimental data can reflect the real work of PGHP. As the physical properties of quartz glass and metal aluminum alloy are much different, a transparent quartz glass is used as the visualizable window, and the rest is made of opaque aluminum alloy, which constitute the SVPGHP. Secondly, considering the practicality of the SVPGHP, the working fluid in the heat pipe evaporates to produce saturated steam, which requires the design of PGHP to have a certain pressure capacity. Currently, the fully visualizable PGHP is made by welding technology. Due to the existence of thermal stress in the welding process, the pressure capacity of the heat pipe is greatly reduced, which leads to the limitation of working pressure. Therefore, a SVPGHP with relative high pressure is introduced in this study. The changes of the working fluid in the experimental process are directly observed through a visualizable window using a high quality camera. The comprehensive analysis of the experimental phenomenon is carried out. The results presented in this paper may help to understand the interior heat exchange mechanism of the PGHP and provide new insight for improving the heat transfer performance of the PGHP. The semi-visualizable experimental method also has some reference value for the study of cavitation.

\section{Experimental}

The manufacturing process of SVPGHP mainly includes the processing of the semi-visualizable plate gravity heat tube shell, the cleaning, drying, sealing test, vacuum and liquid injection of PGHP.

\subsection{Fabrication of SVPGHP Shell}

During the experiment, in order to better observe the change of working fluid, it is necessary to select the material of visualizable window for the light transmittance. Considering the special properties of acetone in the experiment process, the shell material must be specifically and preferably stable and should not react with the acetone reagent. Quartz glass is suitable for the experimental setup, as it has a low thermal expansion coefficient, low thermal conductivity, high temperature resistance, excellent chemical stability, good electrical insulation, optimum transmittance, and high mechanical property.

In the early stage of the experiment, the method of quartz glass welding was used to fabricate the SVPGHP, but it could not meet the pressure requirement of PGHP. In view of this, a special sealant was used for sealing during manufacturing of SVPGHP. Considering the pressure capacity of PGHP, 
quartz glass was used for the window of observation, and aluminum alloy was chosen for the rest of the equipment. In order to ensure the cavity size of PGHP, a groove of $130 \mathrm{~mm} \times 10 \mathrm{~mm} \times 240 \mathrm{~mm}$ was milled on an aluminum alloy plate of $160 \mathrm{~mm} \times 16 \mathrm{~mm} \times 270 \mathrm{~mm}$. On this basis, a smaller groove of $100 \mathrm{~mm} \times 2.5 \mathrm{~mm} \times 210 \mathrm{~mm}$ was milled out again, as shown in Figure 1 . Then the milled groove was covered with a quartz glass plate of $130 \mathrm{~mm} \times 10 \mathrm{~mm} \times 240 \mathrm{~mm}$, and sealed with the special sealant. After standing for $24 \mathrm{~h}$, another aluminum alloy plate, with the external dimensions of $160 \mathrm{~mm} \times 6 \mathrm{~mm}$ $\times 270 \mathrm{~mm}$ and the internal dimensions of $130 \mathrm{~mm} \times 6 \mathrm{~mm} \times 240 \mathrm{~mm}$, was capped with the previously sealed cavity and fastened with screws. Three holes with diameter of $1.5 \mathrm{~mm}$ were processed to insert the thermocouples with a diameter of $1 \mathrm{~mm}$ at different positions on one side of wall surface of PGHP in order to detect the temperature changes in the heat pipe during the test. Finally, a hole with a diameter of $8 \mathrm{~mm}$ was made at the bottom of the aluminum alloy to weld the tube for vacuum and liquid injection. Thus the tube shell of the PGHP was completed. Figure 2a is a dismantled parts diagram of the SVPGHP, and Figure $2 b$ shows an assembly diagram of the SVPGHP.
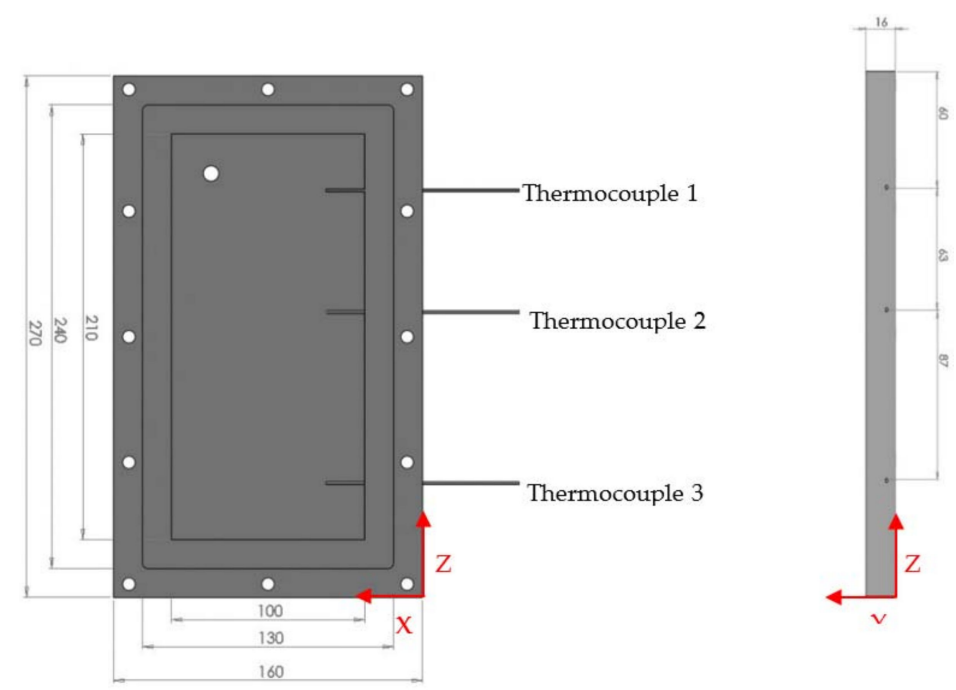

Figure 1. Schematic diagram of the grooved structure of the bottom plate of the semi-visualized plate gravity heat pipe (SVPGHP) (unit: $\mathrm{mm}$ ).

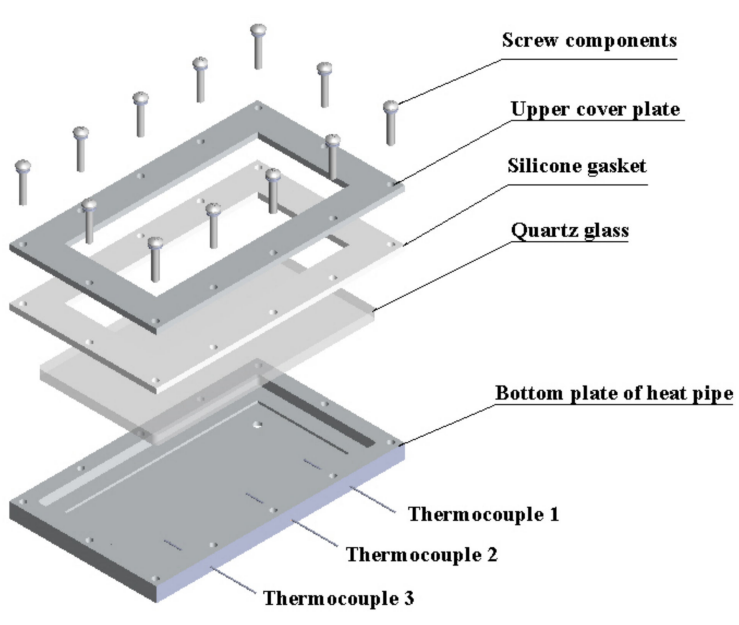

(a)

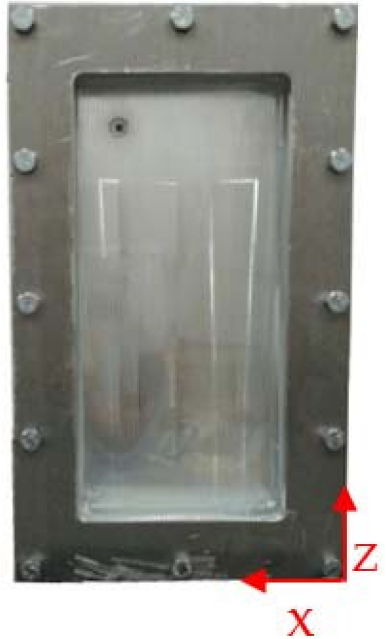

(b)

Figure 2. Dismantled parts (a) and assembly (b) diagrams of the SVPGHP. 
The tests of air tightness and pressure capability of the PGHP were carried out by using an air compressor before conducting the experiment. As the required working pressure of the PGHP was $0.3 \mathrm{MPa}$, for the sake of safety an air compressor of a relatively higher capacity $(0.45 \mathrm{MPa})$ was used to test the internal pressure of the PGHP. After $24 \mathrm{~h}$, if the number of pressure gauges remained unchanged at $0.45 \mathrm{MPa}$, it was considered that the PGHP was well sealed. After completion of the test for tightness and pressure capacity, the vacuum injection operation was performed for the sealed plate gravity tube shell. Figure 3 is a schematic diagram of the vacuum injection for the SVPGHP.

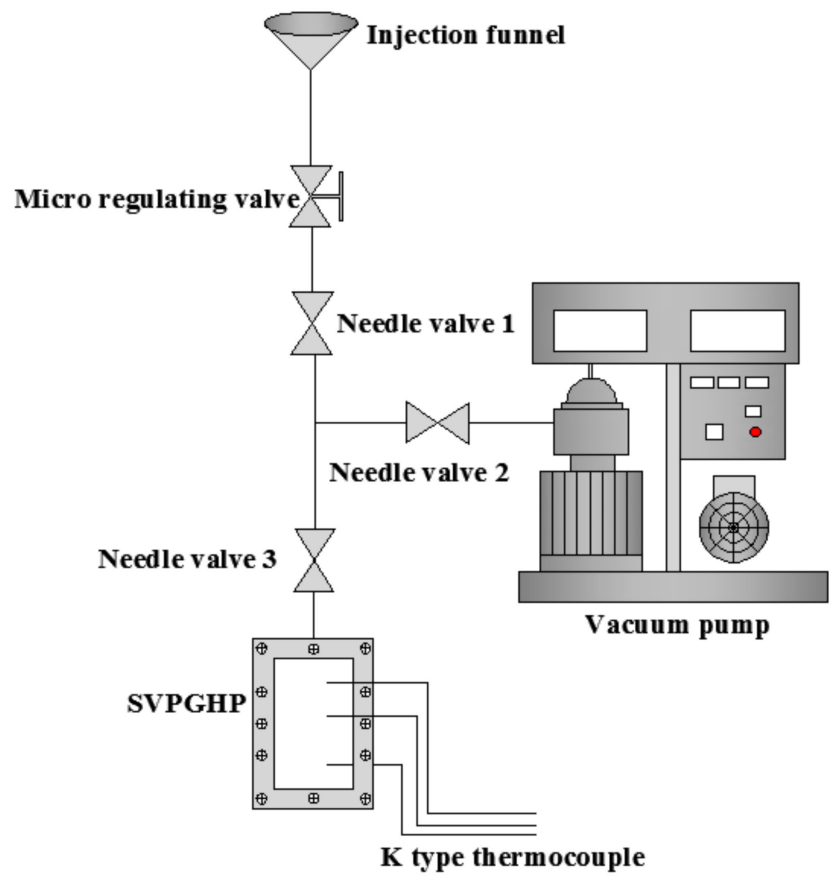

Figure 3. A schematic diagram of vacuum injection for the SVPGHP.

\subsection{Introduction of Experimental System}

Figure 4 is the schematic diagram of the experimental device. The experimental system is composed of different components: the visualizable heat pipe with heating, cooling, lighting, and data acquisition systems. Figure 4 shows the heating (red) and cooling (blue) zones of the heat pipe. In the heating system, the evaporation section of the heat pipe was heated by the heating block $(100 \mathrm{~mm} \times 10 \mathrm{~mm} \times 90 \mathrm{~mm}$ in size) installed on the aluminum alloy wall and the heating power input was controlled by a voltage regulator. In order to reduce the contact resistance between the heating block and wall of heat pipe, thermally conductive silicone grease was used to strengthen the heat transfer process. In the cooling system, the condensation section of the heat pipe was cooled by forced air at room temperature of $21^{\circ} \mathrm{C}$ kept constant by air conditioning from the axial-flow fan, and the air flow rate was regulated by the air valve. In order to monitor the change of the temperature in the heat pipe during the experiment at any moment, three K-type thermocouples with an error of $\pm 1.5^{\circ} \mathrm{C}$ were arranged at different positions on the Z-axis of the heat pipe, and the temperature data of the working fluid in the heat pipe were recorded in the computer. Meanwhile, in order to clearly observe the change of the flow pattern during the working process of the heat pipe, a high-speed i-SPEED3 camera was installed in the experiment. Before performing the experiment, the resolution of the high-speed camera was adjusted to $600 \times 800$ pixels. In addition, the distance between the camera and the heat pipe, especially, the brightness and focal length of the camera were adjusted to achieve the best effect of observation. In order to minimize heat loss, measures using insulation cotton wrapped around the heating and cooling sections of aluminum plate have been taken during the experiment. 


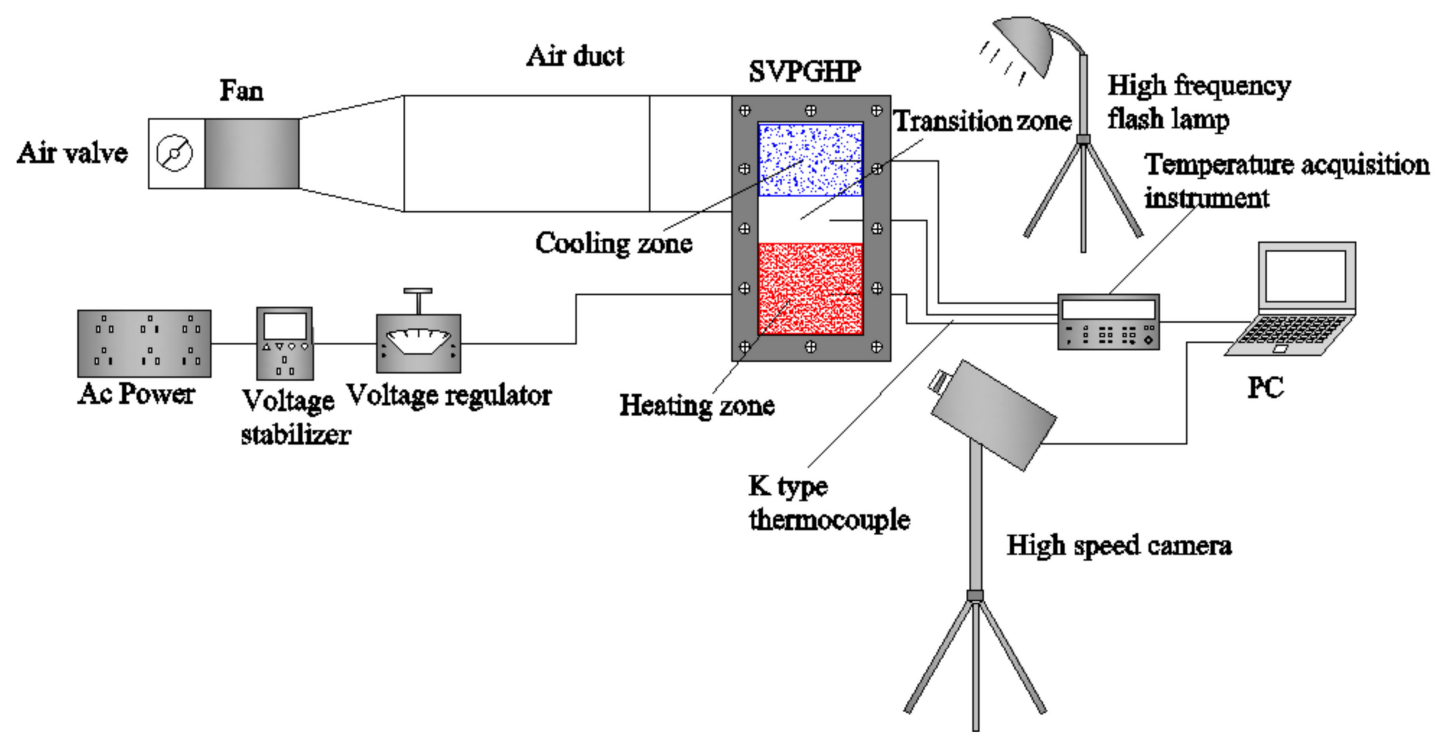

Figure 4. Test system of the SVPGHP.

\subsection{Experimental Conditions}

The considered operating conditions include heating power input, vacuum degree and filling ratio, where vacuum degree refers to the internal pressure value of heat pipe without working fluid before liquid injection, and the internal pressure varies with the working fluid temperature due to heat transfer after injection. In the current work, the effects of experimental conditions on the start-up temperature, start-up time, temperature difference and relative thermal resistance on the Z-axis of the PGHP in a vacuum of $1 \times 10^{-3}$ Pa were studied. At the same time, the gas-liquid two-phase behavior of the interior working fluid of PGHP and the coupling heat transfer behavior between the boiling liquid and the condensate were observed through a visualizable window under different experimental conditions as illustrated in Table 1.

Table 1. Experimental conditions.

\begin{tabular}{ccc}
\hline Experimental Parameters & Values & Units \\
\hline Heating power & $80,100,120,140,160,180$ & $\mathrm{~W}$ \\
Vacuum degree & $1 \times 10^{-3}$ & $\mathrm{~Pa}$ \\
Filling ratio & $25,48,55$ & $\%$ \\
\hline
\end{tabular}

\section{Experimental Results and Discussion}

\subsection{Analysis of Start-Up Characteristics}

The heat pipe undergoes a start-up process from the beginning of heating in the evaporation section of the PGHP to a final stable operation. In the start-up process, the evaporation surface begins to generate bubbles, and then they grow and break away from the surface. Moreover, the liquid near the heating surface forms a complex fluid flow under the interaction of bubbles.

With the absolute pressure of the inner cavity of the PGHP at $1 \times 10^{-3} \mathrm{~Pa}$, the working fluid filling ratio at $55 \%$ and the heating power input of $120 \mathrm{~W}$, the central temperature in the evaporation section of PGHP increases with the rise of heating time, as shown in Figure 5. Furthermore, when the heat pipe starts to work at a given heating power input, there is a certain variation of the temperature curve of the evaporation section. The prompt change of temperature is mainly manifested as follows: the temperature suddenly reduces to some extent and then rises up again in the heating stage. The reasons include that the interior working fluid absorbs heat continuously, which results in energy 
accumulation. Thus its temperature increases constantly before the start-up of heat pipe. In the meantime, the fluid level of working fluid in heat pipe is calm, so there is no sharp change on the temperature curve of the evaporation section during this period. In the meantime, the fluid level of working fluid in the heat pipe is calm, so there is no sharp change on the temperature curve of the evaporation section during this period. However, with the constant input of heat, the working fluid achieves a certain degree of superheat. This heat is required by the working fluid to generate nucleation sites. Then the heat pipe starts to run. During the operation of the heat pipe, these nucleation sites will rise and grow in a relatively short time, which will lead to a series of complex gas-liquid two-phase behavior changes. After a period of time, the working fluid in the heat pipe begins boiling to produce saturated steam. The saturated steam will take away a lot of latent heat when it rises up, which causes a sudden drop of the interior temperature in the evaporation section of the heat pipe. Certainly, the saturated steam, with the continuous input of exterior heat, rises up to the condensation section, releases heat and condenses to liquid. And the condensate which returns to the evaporation section will continue absorbing heat to increase the temperature further.

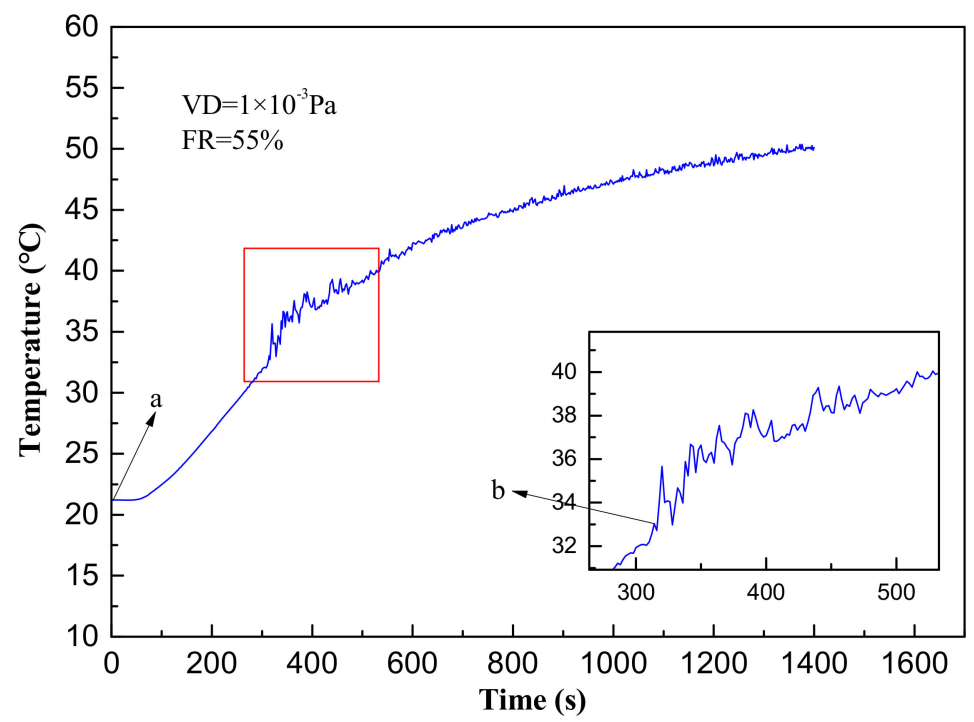

Figure 5. The variation of temperature on evaporation section of PGHP with heating time at $120 \mathrm{~W}$. FR denotes working fluid filling ratio, VD denotes vacuum degree. Points $a$ and $b$ denote the positions of beginning heating time and start-up time, respectively.

In this paper, the time of the first fluctuation in temperature was defined as the start-up time $t_{s t}$, and the corresponding temperature was defined as the start-up temperature $T_{\text {st }}$. It can be seen from the left side of Figure 5 that the start-up time of the PGHP is the time interval (about $320 \mathrm{~s}$ ) between the points $a$ and $b$, and the start-up temperature of the PGHP is the temperature which is corresponding to the point $b$ (around $33^{\circ} \mathrm{C}$ ). Figure 6 reveals that the start-up temperature and the start-up time of PGHP change with the heating power input at the working fluid filling ratio of $48 \%$. With the increase of heating power input, the start-up temperature of the PGHP increases and the start-up time decreases. Therefore, the surface of the evaporation section requires more heat and less time to produce bubbles. This is mainly due to the increase of heating power input, leading to less time required for heat accumulation in the interior working fluid of the PGHP, the production of enough heat to generate nucleation sites, and promote the start-up of the heat pipe. Moreover, it is beneficial for heat transfer of the heat pipe, which can guarantee the efficient delivery of heat through the phase transition process of the PGHP. 


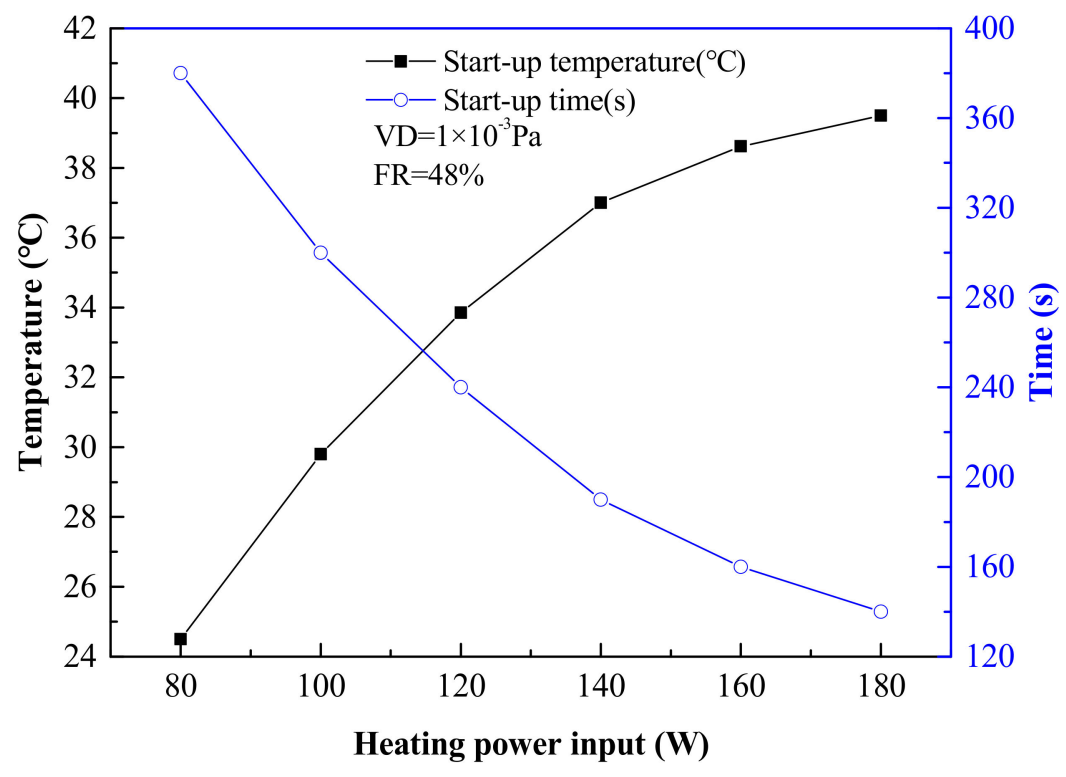

Figure 6. Effects of heating power input on start-up performance of the plate gravity heat pipe (PGHP).

Figure 7 shows the temperature difference on the Z-axis of the PGHP changing with the heating time. The general trend is that the temperature difference sharply increases to reach a peak and then reduces gradually to achieve a steady state at each heating power input as time goes on. The higher the heating rate is, the shorter the peak time. The start-up time is shortened and the start-up temperature difference is increased as the heating power input increases. The reason is that the temperature of the evaporation section increases rapidly as time extends before the start-up of the heat pipe. Meanwhile, the heat transfer of the heat pipe is quite weak, which is due to relatively lower temperature rise in the condensation section than in the evaporation section.

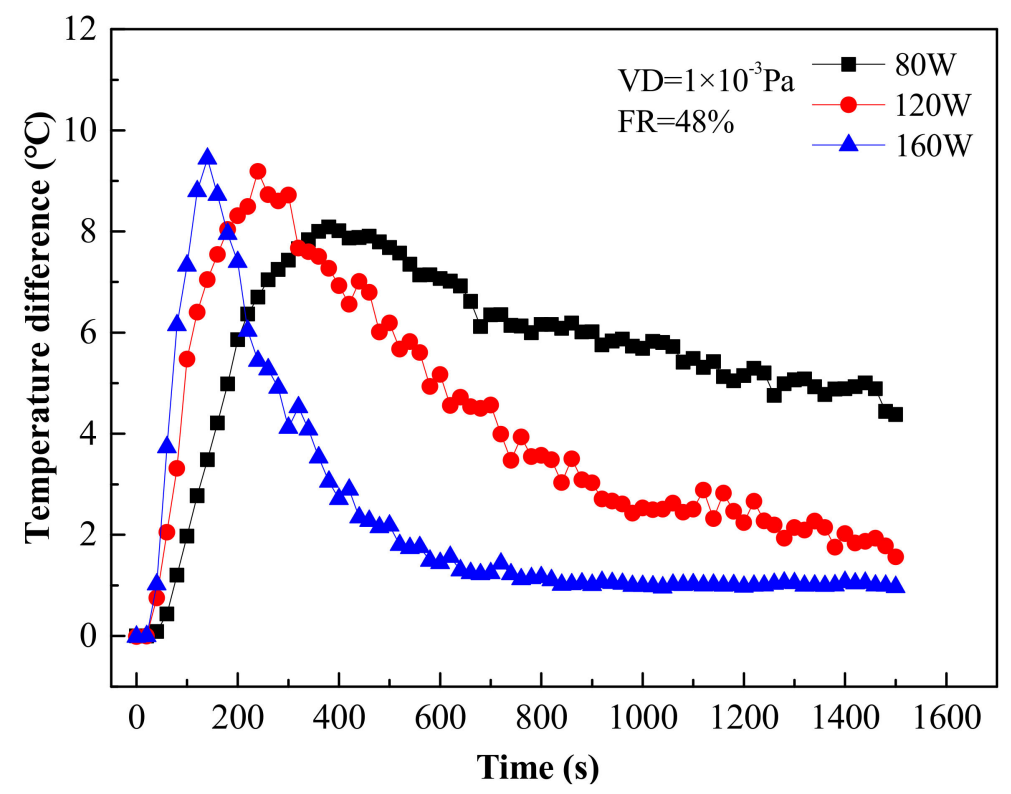

Figure 7. Temperature difference on the Z-axis of the PGHP changing with time under different heating power inputs.

Figure 8 shows the temperature difference on the Z-axis of the PGHP changing with different liquid filling ratios. The changing trend of temperature difference on the Z-axis of the PGHP under different 
liquid filling ratios is the same with those under different heating power inputs. However, the temperature difference on the Z-axis of the PGHP at the liquid filing ratio of $48 \%$ is lower than that of $25 \%$ and $55 \%$. The following visualizable research can explain the difference. The liquid filling ratio has a great influence on the heat transfer performance of the PGHP.

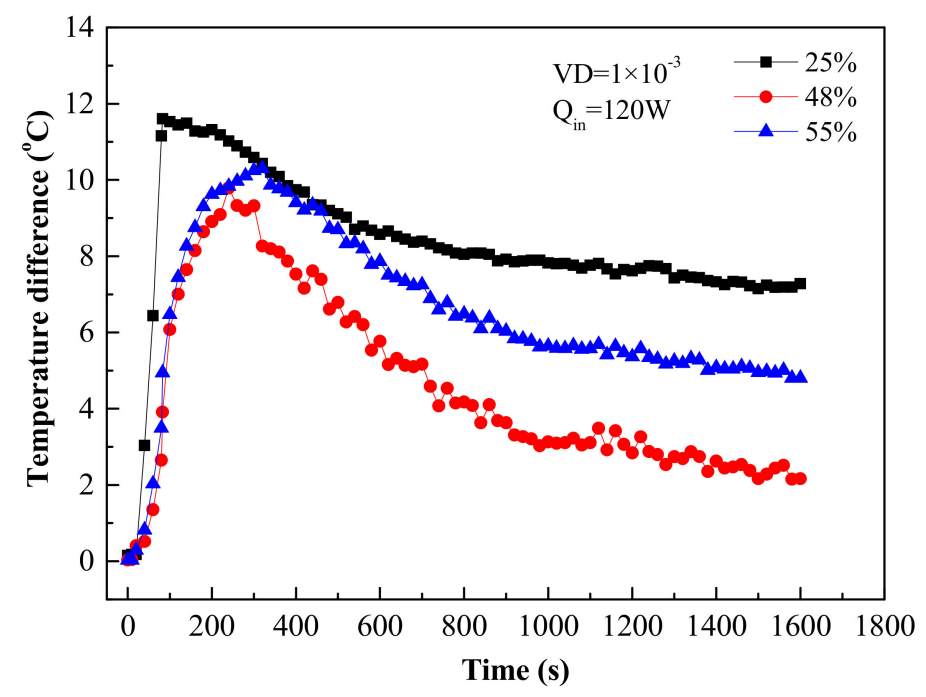

Figure 8. Temperature difference on the Z-axis of the PGHP changing with time under different liquid filling ratios. $Q_{\text {in }}$ denotes input power of evaporation section.

Figure 9 demonstrates the start-up time of the PGHP changing with the heating power input under different fluid filling ratios. The start-up time decreases as the heating power input increases. Comparing the three curves, it can be seen that the start-up time increases with the rise of the working fluid filling ratio under the same heating power input. The reason is that the thermal mass of the working fluid in the heat pipe is small when the working fluid filling ratio is lower at a certain heating power input, which indicates that the working fluid filling ratio of the heat pipe also has a significant impact on the start-up time.

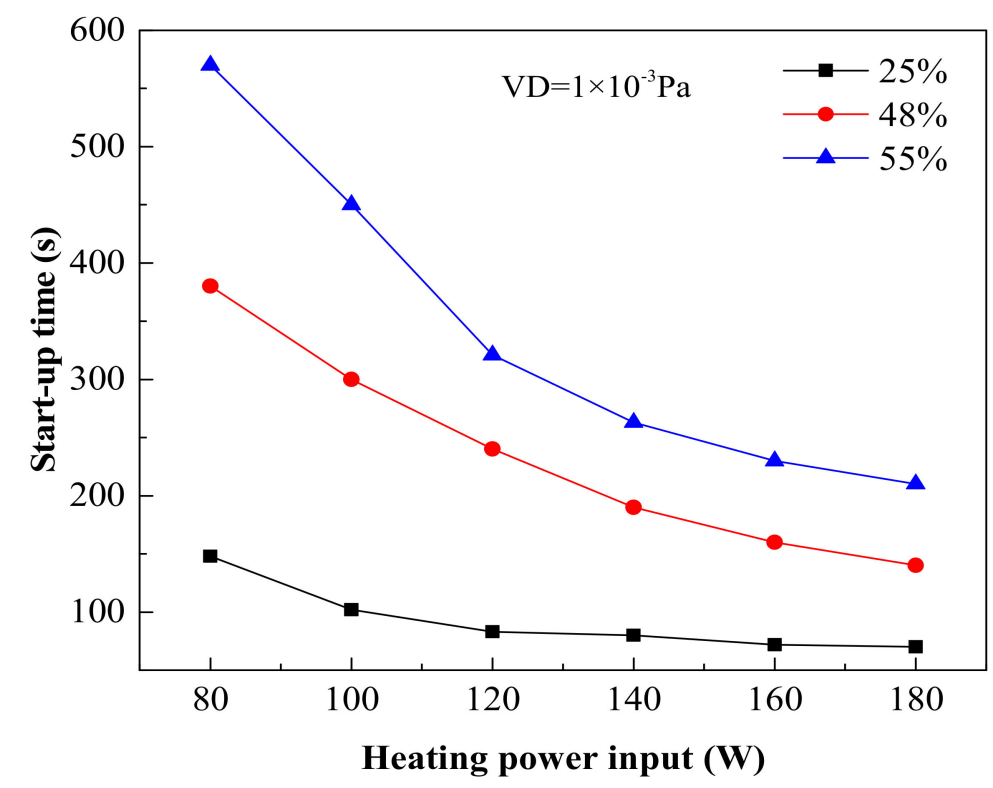

Figure 9. The variation of the start-up time of the PGHP with the heating power input at different fluid filling ratios. 


\subsection{The Temperature Distribution of the Z-Axis in the Steady Operation}

The PGHP is a kind of heat conduction element with excellent thermal conductivity and good isothermal properties. The upper space of the interior of heat pipe is full of saturated steam, and the pressure of the saturated steam corresponds to the saturation temperature. When the saturated steam rises from the evaporation section to the condensation section, there will generate a small pressure drop, and it is known by Clausius-Clapeyron equation that the temperature change at both ends is significantly small, that is why the PGHP has excellent isothermal properties.

Figure 10 reveals that the temperature of the evaporation section is higher than that of the condensation section, and the temperature difference on the Z-axis of the PGHP at each heating rate is relatively small, which shows that the PGHP has good isothermal properties. Bubbles will not appear on the heat pipe wall even if the temperature exactly rises to the saturation temperature of the working fluid without superheat. During the experiment, a large number of bubbles in the evaporation section of the heat pipe were seen. The growth of these bubbles needs a greater degree of superheat, which shows that the working fluid around these bubbles in the evaporation section of heat pipe is superheated, namely, the average temperature of the working fluid in the evaporation section of the heat pipe is higher than that of the saturated steam in the condensation section. Furthermore, the pressure at position where bubbles generated in the evaporation section is the sum of the vapor pressure in the condensation section and the pressure exerted by the liquid above this position. Therefore, the saturated temperature of the evaporation section is higher than that of the condensation section. Meanwhile, during the stable operation of the heat pipe, the upper portion of the heat pipe is full of saturated steam. The pressure difference between the upper and lower parts of the heat pipe is extremely small, and the temperature difference between the upper and lower parts of the heat pipe is also significantly small, as shown in Figure 10. In addition, the temperature of the heat pipe gradually increases with the rise in heating power input, which further accelerates the heat flux density of the heat pipe. More saturated steam is produced, which increases the internal pressure of the heat pipe along with the corresponding saturated temperature.

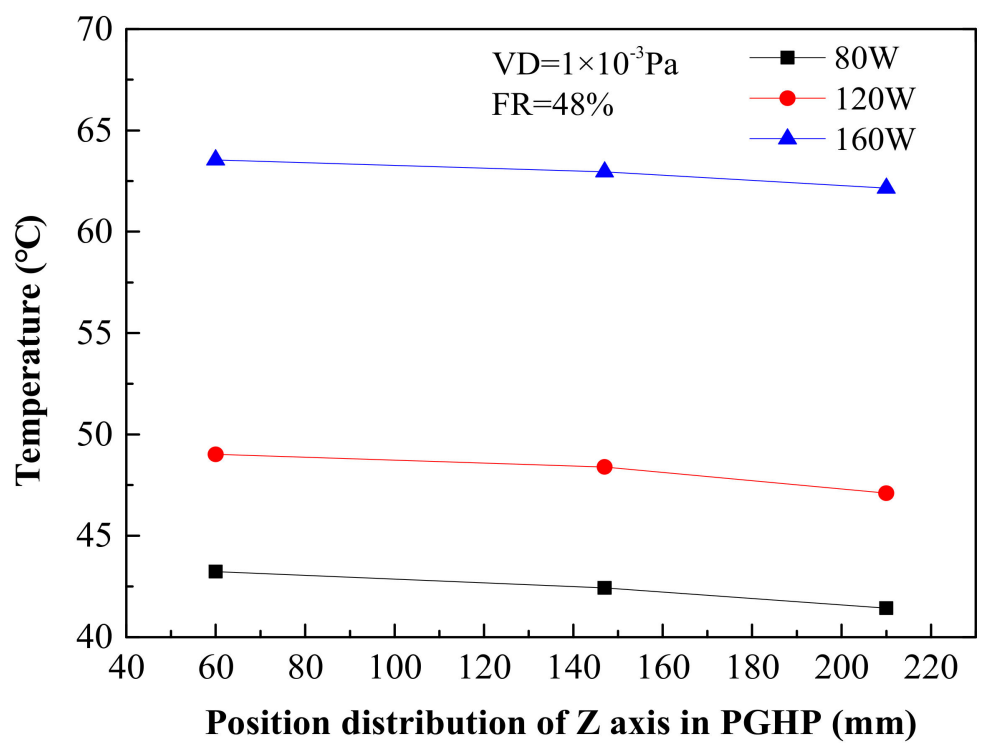

Figure 10. Temperature distribution on the Z-axis of the PGHP at different heating power inputs.

Figure 11 displays the temperature distribution on the Z-axis of the PGHP at different fluid filing ratios. When the liquid filling ratio is $48 \%$, the temperature difference between the evaporation and condensation sections of the PGHP is smaller, which indicates that the PGHP with a liquid filling ratio of $48 \%$ has good temperature uniformity. Thus, when the PGHP operation is stable, the heat transfer performance of the PGHP with the liquid filling ratio of $48 \%$ is better than those of $25 \%$ and $55 \%$. 


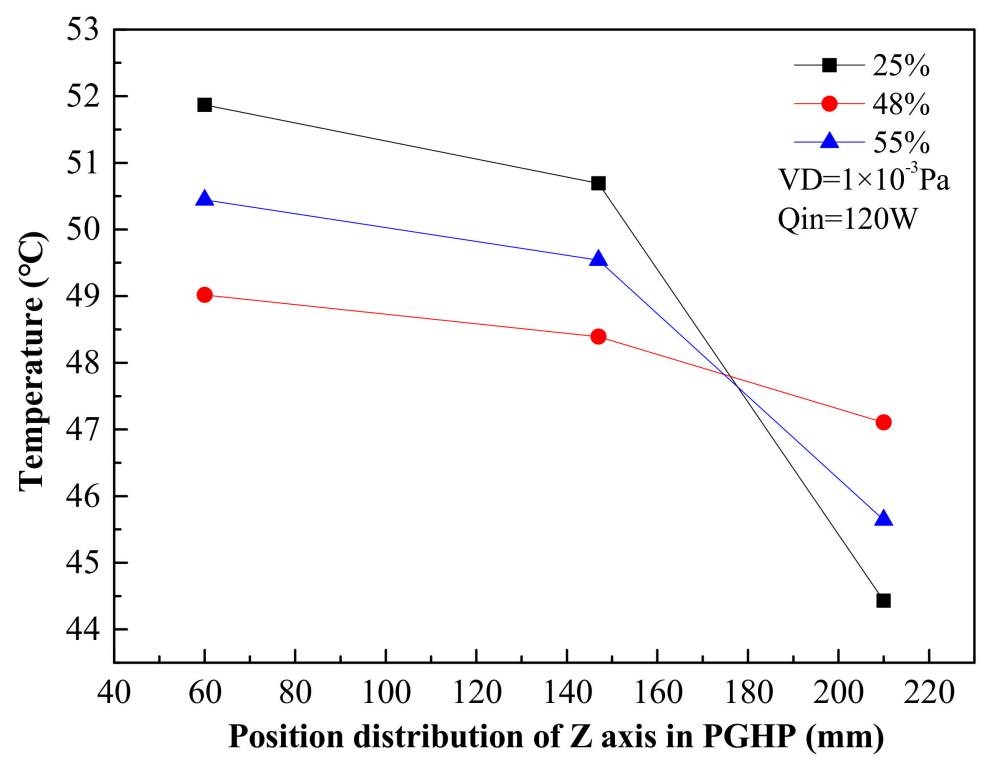

Figure 11. Temperature distribution on the Z-axis of the PGHP at different fluid filing ratios.

\subsection{Analysis of Heat Transfer Performance and Influencing Factors of SVPGHP}

The thermal resistance of the steam chamber in the PGHP represents the temperature difference that is required to transport per unit heat power. It is an important parameter to measure the heat transfer performance of the PGHP. In the present study, the focus has been given to the relative resistance occurring in the working fluid during its evaporation and condensation. Therefore, the relative thermal resistance is proposed to evaluate the heat transfer capacity of the PGHP in this paper, which is defined as Equation (1):

$$
\begin{gathered}
\mathrm{R}=\frac{\Delta T}{Q}, \\
\Delta T=T_{e}-T_{\mathcal{c}},
\end{gathered}
$$

where $R$ is the relative thermal resistance of the working fluid, ${ }^{\circ} \mathrm{C} / \mathrm{W} ; Q$ is the actual heat input to the heat pipe, $W ; \Delta T$ is described by Equation (2) and it represents the average temperature difference between the evaporation and the condensation sections of the cavity in the PGHP, ${ }^{\circ} \mathrm{C} ; T_{e}$ represents the average temperature in the evaporation section of the PGHP measured by thermocouple 3 and $T_{\mathcal{C}}$ represents the average temperature in the condensation section of the PGHP measured by thermocouple $1,{ }^{\circ} \mathrm{C}$. This relative thermal resistance represents the resistance of heat transfer from the heating surface to the condensing surface. The smaller the relative thermal resistance value, the better the overall heat transfer performance of the PGHP cavity will be.

Figure 12 shows the variation of the relative thermal resistance on the Z-axis of the PGHP with the heating time under different heating power inputs. The relative thermal resistance on the Z-axis of the PGHP shows a sharp increase at a certain heating power input before the start-up of the heat pipe. When the heat pipe starts to run, the relative thermal resistance on the Z-axis of the PGHP will drop as the heating time increases, and ultimately maintains a relatively stable value. Meanwhile, the relative thermal resistance on the Z-axis displays a downward trend with the increase of the heating power input. The heat transfer in the heat pipe is based primarily on the conduction of the liquid medium before the start-up of the heat pipe, so the heat transfer of the heat pipe is extremely low, however, when the heat pipe starts to run with the increase of heating power input, the cavity in the heat pipe will produce more bubbles, and more heat will be transmitted through the formation of bubbles on the evaporation surface and the condensation of vapor on the condensation surface. In addition, the movement of the bubbles will lead to the disturbance of the boiling liquid near the heating surface and the interaction between bubbles, boiling fluid, and condensation surface to become 
more and more intense. Therefore, the heat transfer capacity of the PGHP cavity is strengthened with less thermal resistance.

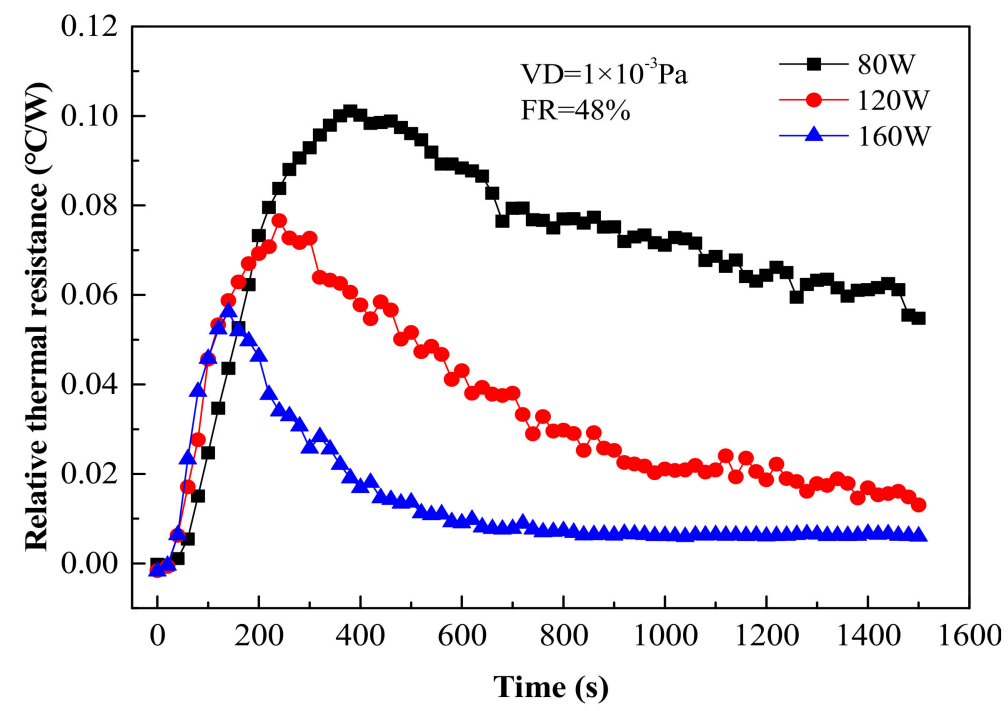

Figure 12. The relative thermal resistance on the Z-axis of the PGHP changing with heating time under different heating power inputs.

Figure 13 displays the variation of the relative thermal resistance on the Z-axis of the PGHP with the heating time under different liquid filling ratios. The changing trend of relative thermal resistance with time is almost similar to the trend of temperature difference in Figure 8.

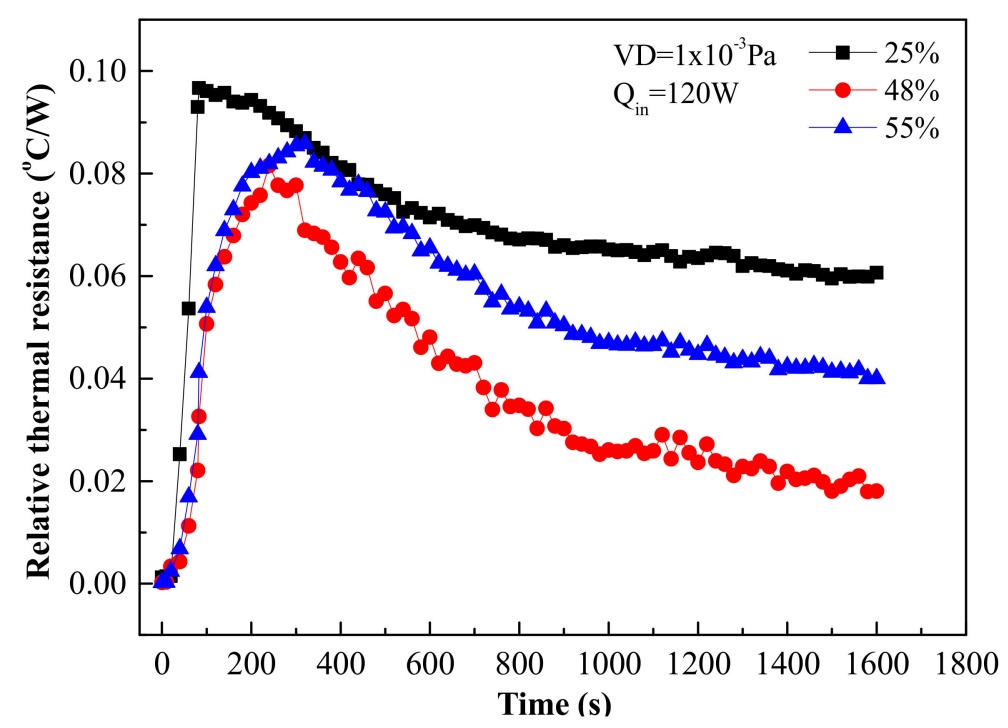

Figure 13. The relative thermal resistance on Z-axis of PGHP changing with heating time under different liquid filling ratios.

Figure 14 displays three curves of the relative thermal resistance on the Z-axis of the PGHP decreasing as the heating power input increases under different fluid filling ratios. The relative thermal resistance in the heat pipe at the liquid filling ratios of $25 \%$ and $55 \%$ are relatively larger than that at the filling rate of $48 \%$. It means that the relative thermal resistance on the Z-axis of the PGHP decreases firstly and then increases with the increase of the working fluid filling ratio under a certain heating power input. Keeping the liquid filling ratio lower at a certain heating power, the thermal mass of the working 
fluid will be smaller. It will take a relatively shorter start-up time. Consequently, more bubbles will be generated. The working fluid is heated to produce saturated steam, which rises to the condensation section. The evaporation rate is higher than the condensation rate, so that the liquid cannot be returned to the evaporation section in time. In addition, the condensate film becomes thicker in the condensation section, which results in the increase of the thermal resistance and reduction of the heat transfer coefficient of the condensation section. However, at the higher working fluid filling ratio, the distance from the liquid level of working fluid to the top of the condensation section is smaller so that the boiling liquid contacts or covers the condensation surface for a long time. It hinders the condensation of saturated steam on the condensation surface and affects the condensation heat transfer of the heat pipe and then limits the overall heat transfer capacity of the heat pipe. When the liquid filling ratio of heat pipe is $48 \%$, bubbles can easily overflow from the liquid. Meanwhile, the liquid film on the condensation section can return to evaporation section, which makes the relative thermal resistance inside the heat pipe lower. Thus, the working fluid filling ratio of the heat pipe should be kept within a certain range, where the interaction between the evaporation, the boiling and the condensation heat transfer will reach an optimum level, which leads to the best thermal performance of the plate heat pipe cavity.

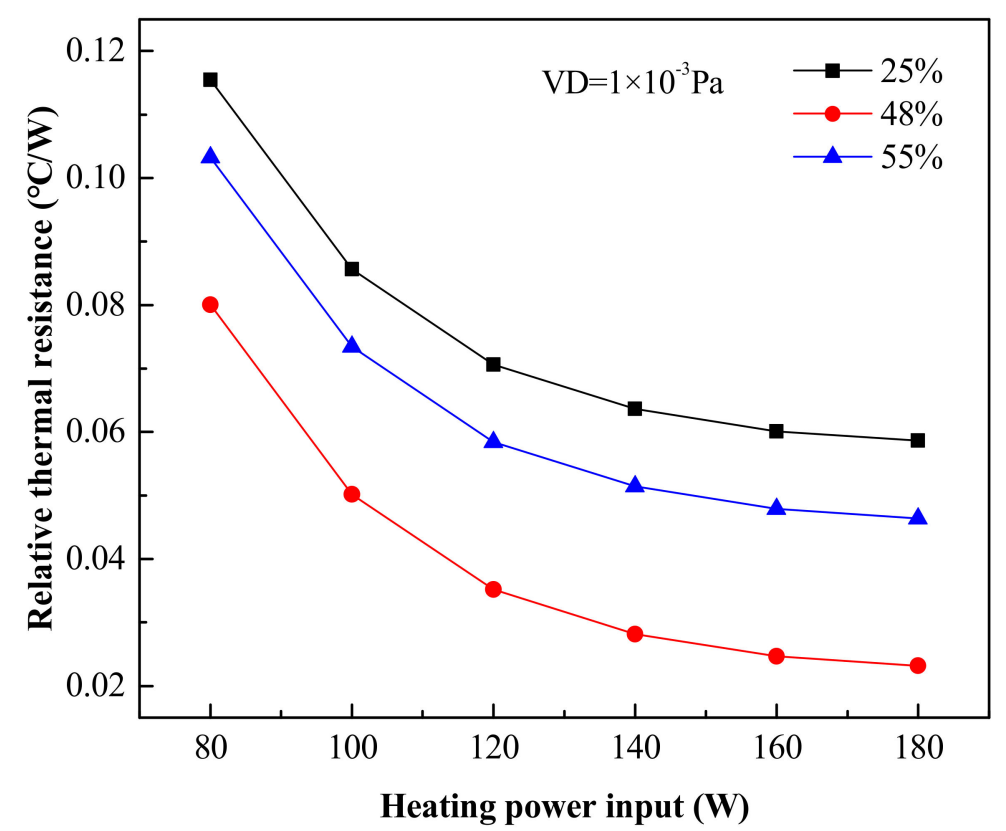

Figure 14. The relative thermal resistance on Z-axis of PGHP changing with heating power input under different fluid filling ratios.

The actual heat transfer $\left(Q_{a c}\right)$ of the heat pipe is tested in the cooling zone, which is calculated by Equation (3).

$$
Q_{a c}=\rho V C_{p}\left(T_{o}-T_{i}\right)
$$

where $C_{p}$ is the specific heat at constant pressure of air, $\mathrm{J} / \mathrm{kg} .{ }^{\circ} \mathrm{C} ; \rho$ is the density of air, $\mathrm{kg} / \mathrm{m}^{3} ; V$ is the volumetric flow of air, $\mathrm{m}^{3} / \mathrm{s} ; T_{0}$ is the air outlet temperature, ${ }^{\circ} \mathrm{C} ; T_{i}$ is the air inlet temperature, ${ }^{\circ} \mathrm{C}$.

It can be seen from Figure 15 that the actual heat transfer of the PGHP varies with the heating time at $160 \mathrm{~W}$. In the unsteady stage, the actual heat exchange of the PGHP increases with the increase of heating time. After $600 \mathrm{~s}$, the operation of the PGHP reaches a steady state, and the actual heat transfer of PGHP becomes almost constant. In addition, it can also be seen that its actual heat transfer is close to the input power value of the heat pipe after reaching a steady state, and the heat loss is very small, which accounts for $3.1 \%$ of the input power. 


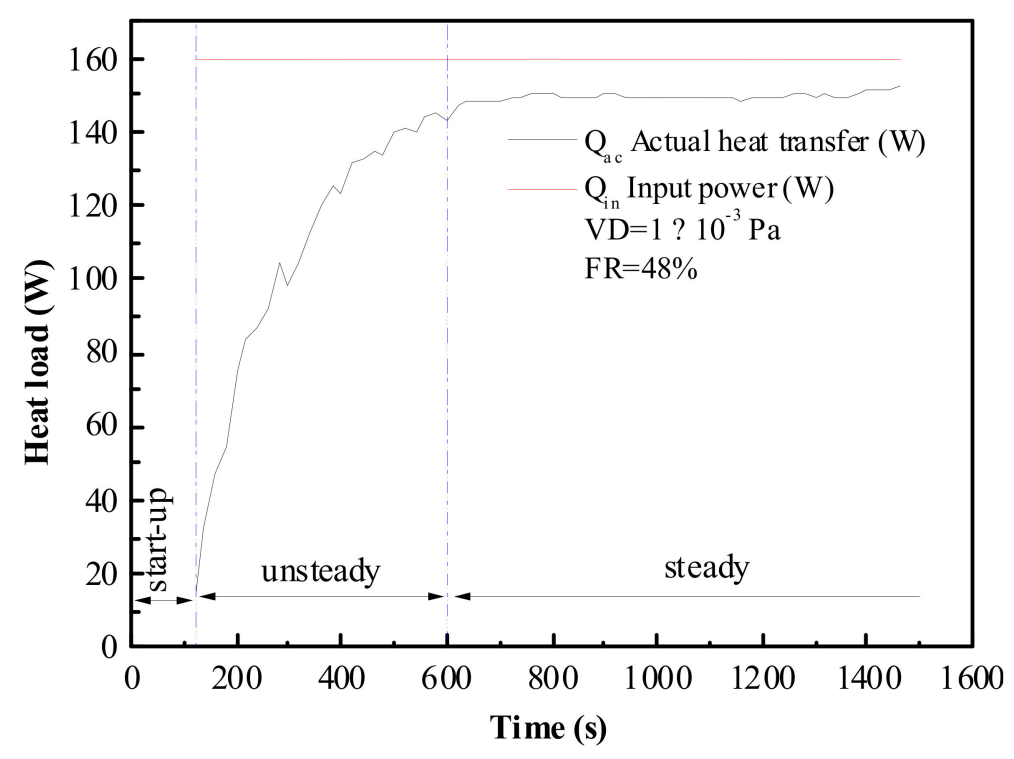

Figure 15. The heat load variation with heating time of the PGHP at $160 \mathrm{~W}$.

\subsection{Visualization Analysis of Gas-Liquid Two-Phase Flow in PGHP}

It is difficult to imagine the simultaneous coexistence of the phase change heat transfer process of evaporation and condensation in the small cavity of the PGHP. Along with these phase transition processes, there is a variety of hydrodynamic behaviors between the gas and liquid in the cavity of the PGHP, such as the generation, growth, movement, convergence, and break up of bubbles, as well as the condensation of saturated steam and the fluctuation of working fluid. These complex gas-liquid two-phase behaviors coexist and interact in the cavity of the PGHP, and play a key role in the process of the operation and effective heat transfer of the PGHP. The visualization analysis can provide the clear understanding of the heat transfer process.

\subsubsection{Nucleate Boiling and Bubble Growth}

When the working fluid in the evaporation section of the PGHP is heated continuously to reach a saturated stage, the nucleate boiling phenomenon, which is an important impetus to promote the start-up of the PGHP to the quasi-stable operation stage, will appear in the evaporation section of the PGHP. The nucleate boiling and the generation, growth of bubbles are important characteristics of gas-liquid two-phase behaviors in the evaporation section of the PGHP.

Figure 16 shows the phenomenon of heterogeneous nucleation, that is, bubbles generate from the heating wall of the evaporation section.

As can be seen from Figure 16, the working fluid becomes superheated after absorbing heat. It results in bubble generation on the heating wall surface. Then, the evaporation of liquid film and heat transfer lead to the growth of the bubble. Meanwhile, due to the existence of the negative pressure in the cavity of the PGHP, these bubbles can grow up to a larger volume. When the bubbles reach a certain volume, the bubbles move away from the heating surface and rise under the influence of surface tension and inertia force, which leads to a strong disturbance of the working liquid in the cavity of the PGHP and makes the dynamic behavior of bubbles become more complex. In addition, the vapors or gases above the liquid level in the evaporation section will be brought into the interior of the liquid during the disturbance of the working liquid, which will create conditions for the homogeneous nucleation of the liquid in the later stage.

The homogeneous nucleation phenomenon illustrates the emergence of bubbles from the small nucleation sites that are formed in the low-density region of the working liquid or the gases evolved in the liquid. Due to the coexistence of the heterogeneous nucleation phenomenon of the working fluid 
and the formation, rise and breakup of the bubbles, the disturbance of the working fluid in the cavity of the PGHP will be further strengthened. In the evaporation section, such disturbance is conducive to the vapors to be engulfed by the liquid. Thereafter the phenomenon of homogeneous nucleation will appear in the working fluid after a period of heating and produce the corresponding bubbles as shown in Figure 17.

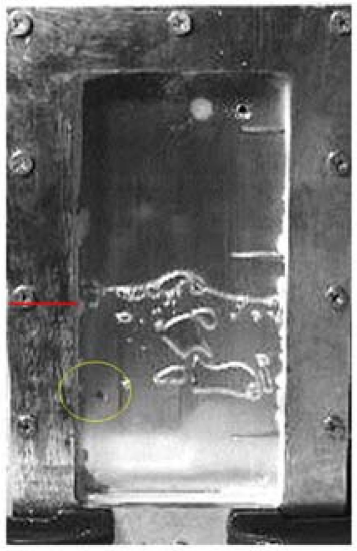

Bubble formation

(a)

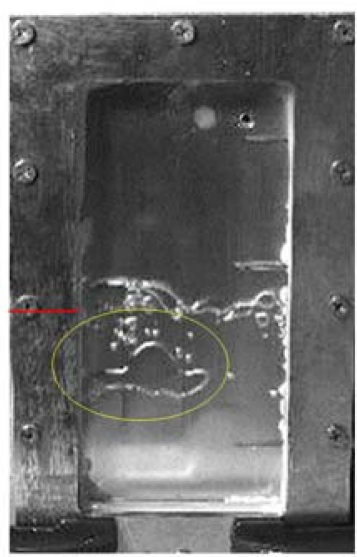

Bubble is growing up

(e)

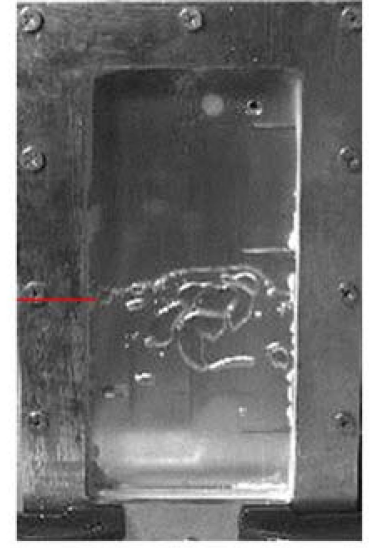

(b)

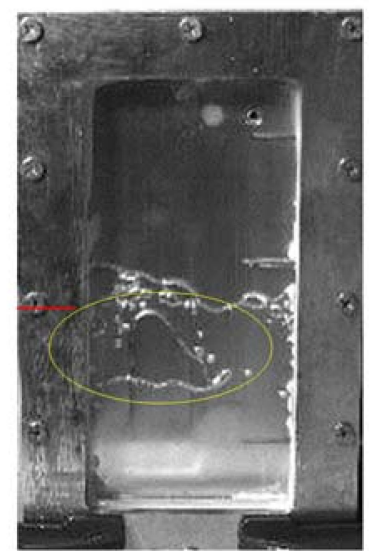

Bubble is

leaving the wall

(f)

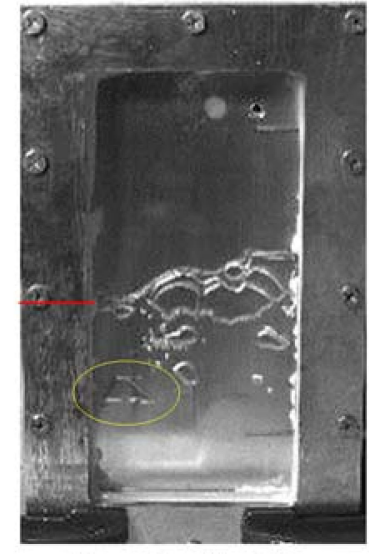

Growth of bubble

(c)

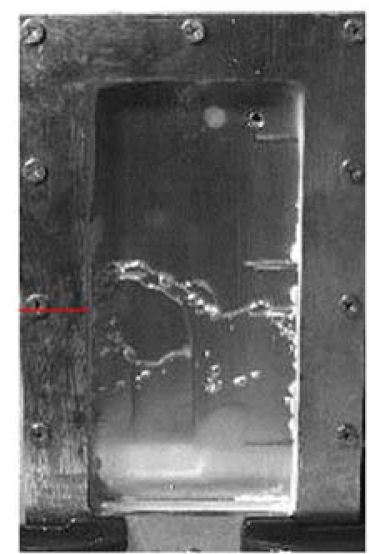

Bubble is rising

(g)

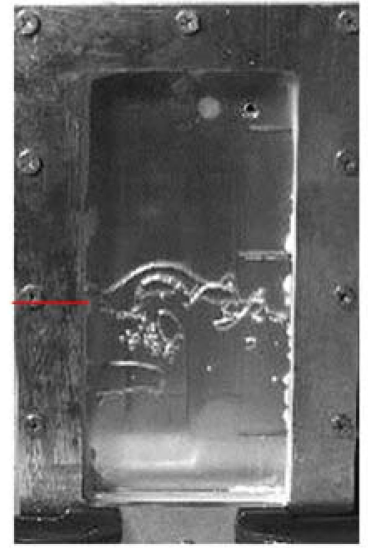

(d)

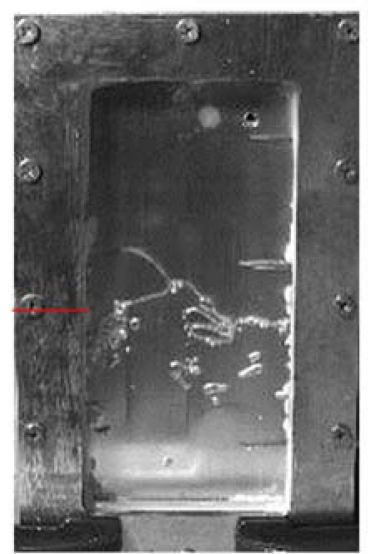

Bubble is breaking up

(h)

Figure 16. Time-series diagram of heterogeneous nucleation and bubble growth in the evaporation section of the PGHP (FR $=48 \%, Q_{i n}=80 \mathrm{~W}, \Delta t=60 \mathrm{~ms}$ ). Note: the initial level is shown as the red line, (a) bubble behavior at $0 \mathrm{~ms}$; (b) $60 \mathrm{~ms}$; (c) $120 \mathrm{~ms}$; (d) $180 \mathrm{~ms}$; (e) $240 \mathrm{~ms}$; (f) $300 \mathrm{~ms}$; (g) $360 \mathrm{~ms}$; (h) $420 \mathrm{~ms}$. 


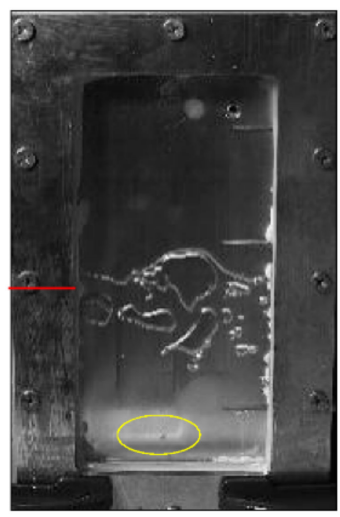

Bubble formation

(a)

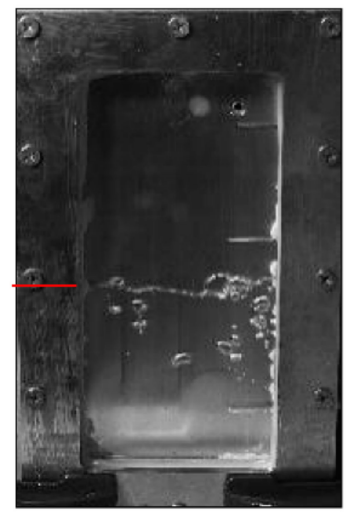

(e)

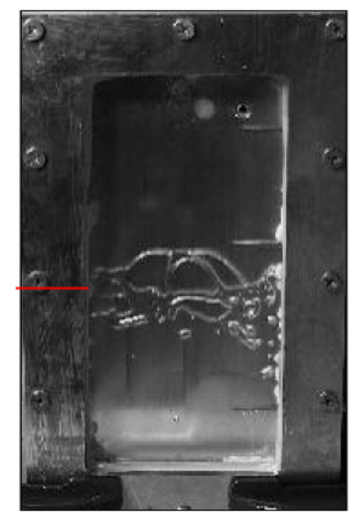

(b)

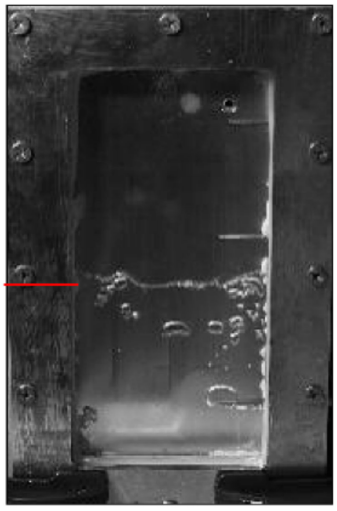

(f)

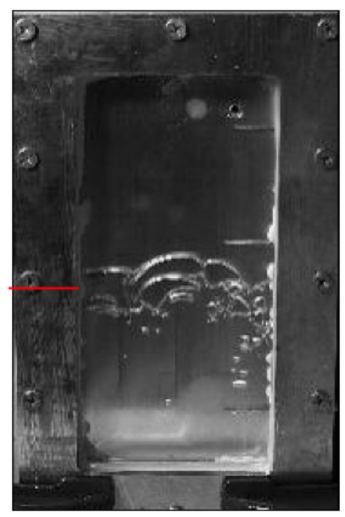

(c)

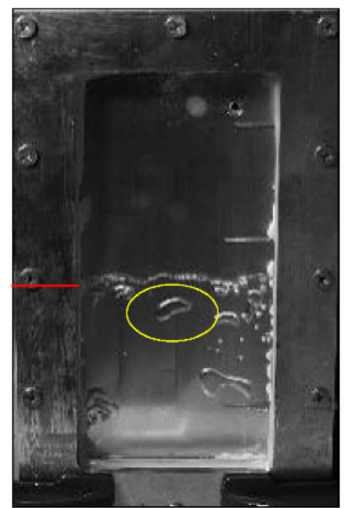

Bubble is growing up

(g)

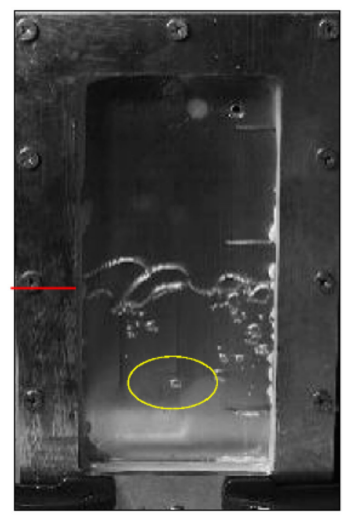

Bubble is rising

(d)

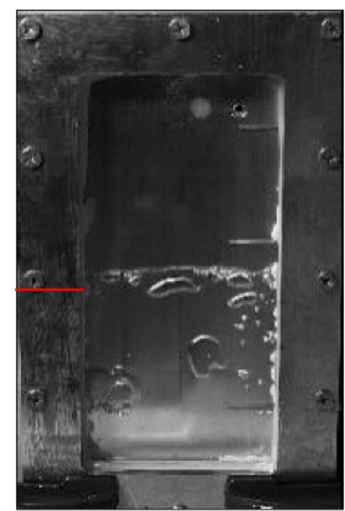

(h)

Figure 17. Time-series diagram of homogeneous nucleation and bubble growth in the evaporation section of the PGHP (FR $=48 \%, Q_{\text {in }}=80 \mathrm{~W}, \Delta t=60 \mathrm{~ms}$ ). Note: the initial level is shown as the red line, (a) bubble behavior at $0 \mathrm{~ms}$; (b) $60 \mathrm{~ms}$; (c) $120 \mathrm{~ms}$; (d) $180 \mathrm{~ms}$; (e) $240 \mathrm{~ms}$; (f) $300 \mathrm{~ms}$; (g) $360 \mathrm{~ms}$; (h) $420 \mathrm{~ms}$.

\subsubsection{The Merging of Bubbles}

Along with the movement and growth of bubbles, the merging phenomenon between two typical bubbles will appear as shown in Figure 18. Two stable bubbles randomly moving in the liquid are affected by the disturbance of the liquid and surrounding bubbles. Under this disturbance, they move to the sides of the two bubbles and then come into contact with each other. At first, the contact surface breaks, and then the two bubbles will gradually merge into one bubble under the influence of surface tension. After convergence, the volume of the bubble is the sum of the two bubbles before merging. The merged bubbles continue to move randomly inside the liquid until they merge with another bubble or grow, condense, rupture under other influences.

There are bubbles 1-3 at the beginning in Figure 14, and $20 \mathrm{~ms}$ later, the sides of the bubbles 1 and 2 contact each other, which break firstly and gradually merge due to surface tension. After a period of time, the sides of the bubbles 3 and 4 contact each other again and repeat the merging process at $73 \mathrm{~ms}$ to form bubble 5 that continues to rise until it reaches the liquid level. In the process of bubble merging, the disturbance of the liquid is accelerated and the process of heat transfer is enhanced. 


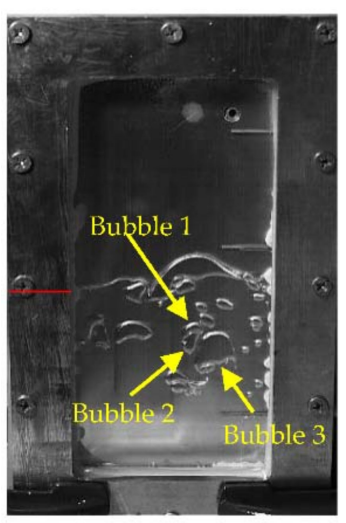

$0 \mathrm{~ms}$

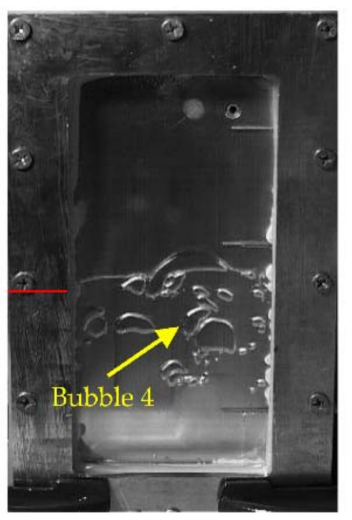

$20 \mathrm{~ms}$

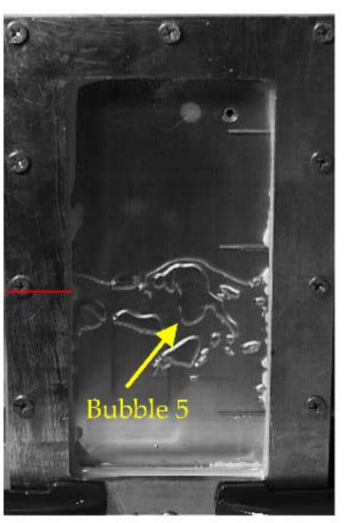

$73 \mathrm{~ms}$

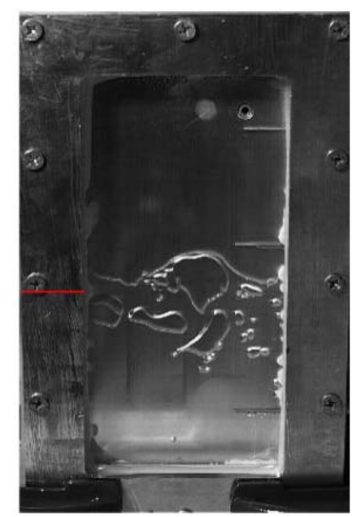

$93 \mathrm{~ms}$

(d)

Figure 18. Time-series diagram of the merging of bubbles in the cavity of the PGHP (FR $=48 \%$, $Q_{\text {in }}=100 \mathrm{~W}$ ). Note: the initial level is shown as the red line, (a) bubble behavior at $0 \mathrm{~ms}$; (b) $20 \mathrm{~ms}$; (c) $73 \mathrm{~ms}$; (d) $93 \mathrm{~ms}$.

\subsubsection{The Breakup of Bubbles}

Figure 19 indicates the breakup of typical bubbles in the cavity of the PGHP. When bubble 6 is big enough, and the speed of the small bubble 7 is fast enough or the suction force of bubble 6 to the small bubble 7 is large enough, the small bubble 7 penetrates the big bubble 6 , thereby causing a strong impact on the big bubble 6 . Then the big bubble 6 is broken into the bubbles 8 and 9 . The bubble 8 will be further cracked under the impact of the bubble 7 and another bubble 10 to form several bubbles with different sizes. In short, the splitting process of bubbles increases the turbulence of the working liquid in the cavity of the PGHP and enhances the heat transfer capacity of the PGHP.

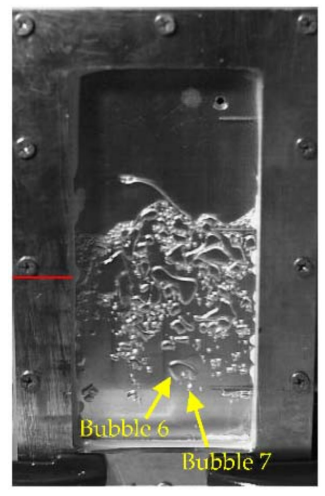

(a)

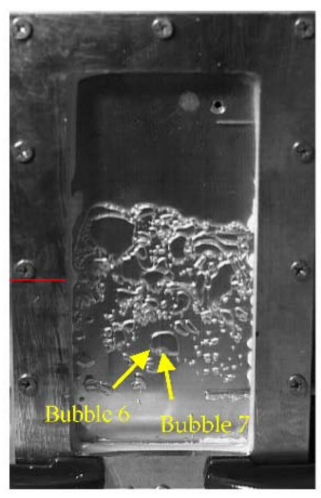

Bubble 7 is attacking bubble 6

(b)

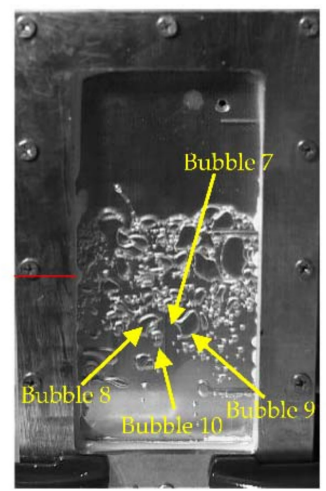

Formed bubbles 8 and 9 . Bubbles 10 and 7 are attacking bubble 8

(c)

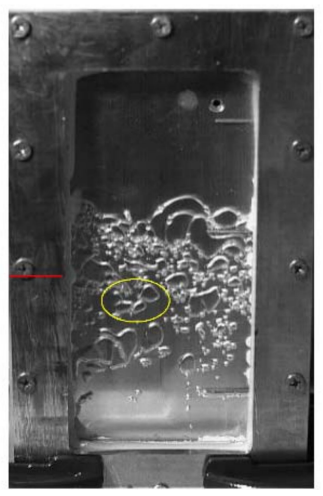

Formed several small bubbles

(d)

Figure 19. Time-series diagram of the breakup of bubbles in the cavity of the PGHP (FR $=48 \%$, $Q_{\text {in }}=120 \mathrm{~W}, \Delta t=52 \mathrm{~ms}$ ). Note: the initial level is shown as the red line, (a) bubble behavior at $0 \mathrm{~ms}$; (b) $52 \mathrm{~ms}$; (c) $104 \mathrm{~ms}$; (d) $156 \mathrm{~ms}$.

\subsection{Analysis of Heat Transfer Performance of PGHP}

\subsubsection{Effects of Heating Power Input}

Based on the results, it is found that the effects of different heating power inputs on heat transfer are different. Therefore, in order to obtain a deeper understanding of the heat transfer mechanism of the PGHP, it is necessary to do an intuitive observation of the working process of PGHP through the visualizable window. The effects of heating power input on thermal resistance are further explained by 
the gas-liquid two-phase hydrodynamic behavior images captured by the high-speed camera during the experiment.

Figure 20 displays an increasing number of bubbles with the increase of heating power input. The reason is that when the heating power input increases, the temperature of the heating surface rises and the superheat of the working liquid increases, so that more nucleation sites are excited and more bubbles arise. The presence of more and more bubbles on the heating surface leads to fierce turbulence of the working fluid, and the convection heat transfer between the working liquid and the heating surface improves, consequently, the boiling heat transfer strengthens. In addition, the condensate on the condensation surface of the heat pipe accumulates continuously with the increase of heating power input. There is no obvious condensation phenomenon at the beginning shown in Figure 20a, but some obvious condensate droplets will appear on the condensation surface with the increase of heating power input. The main reason is that the bubbles and the working fluid in the PGHP have more and more influence on the condensation surface with the increase of heating power input. Moreover, the breakup of the bubble or the scouring action of the boiling liquid on the condensation surface promotes the backflow of the condensate, which reduces the thickness of the liquid film and strengthens the heat transfer capacity of the condensation section. Therefore, the thermal resistance of the cavity drops gradually with the increase of heating power input to witness better heat transfer performance of the PGHP.

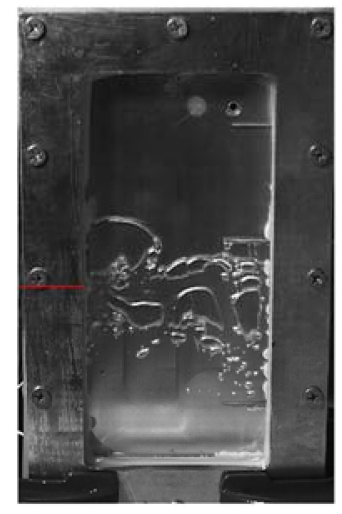

$80 \mathrm{~W}$

(a)

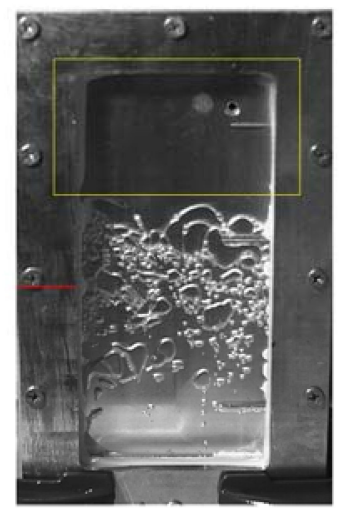

$100 \mathrm{~W}$

Generation area of liquid mist

(b)

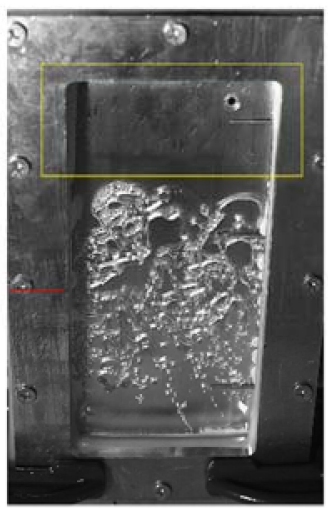

$140 \mathrm{~W}$

Generation area of condensed droplet

(c)

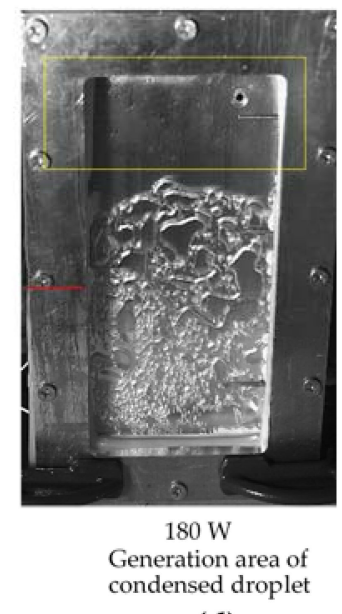

(d)

Figure 20. The images of gas-liquid two-phase behavior in the cavity of PGHP under different heating power inputs ( $F R=48 \%$ ). Note: the initial level is shown as the red line, (a) condensation behavior at $80 \mathrm{~W}$; (b) $100 \mathrm{~W}$; (c) $140 \mathrm{~W}$; (d) $180 \mathrm{~W}$.

\subsubsection{Effects of Working Fluid Filling Ratio}

The work above reveals that the working fluid filling ratio significantly affects heat transfer through the analysis of thermal resistance curve. Following study focuses on the heat transfer mechanism of the PGHP by visual observation.

Figure 21 indicates some typical images of the gas-liquid two-phase hydrodynamic behavior in the cavity of the PGHP at the working fluid filling ratio of $25 \%$, which provides enough space for the growth of the bubble above the liquid level of the working fluid. Therefore, the boiling liquid does not come into contact with the condensate covered on the condensation surface during the operation of the PGHP. In other words, the boiling liquid and condensate are relatively independent in the cavity of the PGHP so that the condensate can be returned only by gravity. In addition, it also leads to bubbles taking a long time to grow, then reduces the frequency of bubble formation. In short, a lower working fluid filling ratio is detrimental to the boiling heat transfer. Meanwhile, a layer of thick liquid film 
covers the condensation surface for a long time, which also hinders the contact between the steam and the condensation surface. Therefore, it is also disadvantageous to the condensation heat transfer.

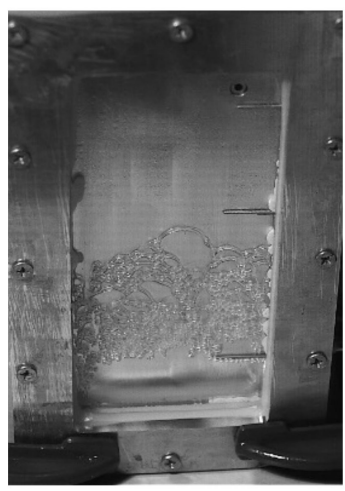

(a)

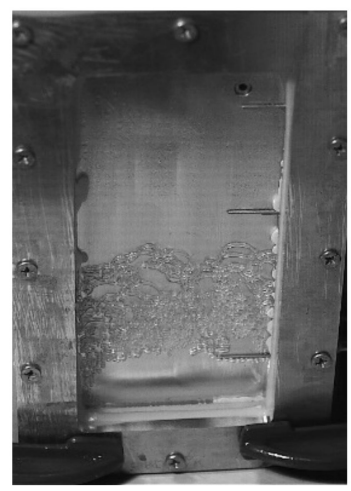

(b)

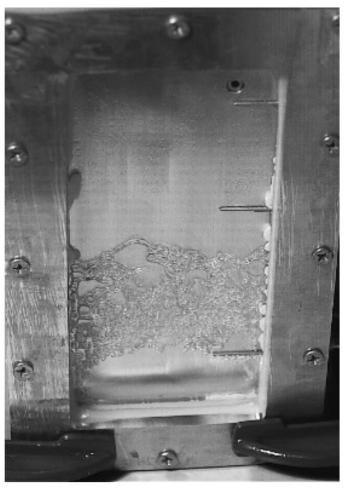

(c)

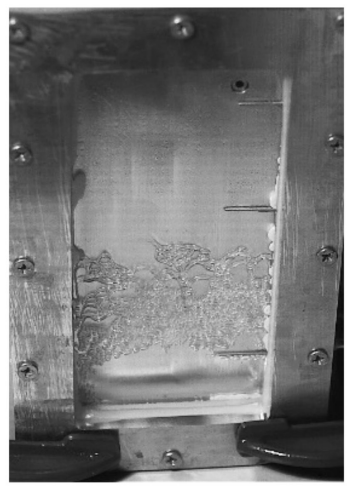

(d)

Figure 21. Typical images of gas-liquid two-phase hydrodynamic behavior in the cavity of the PGHP $\left(\mathrm{FR}=25 \%, Q_{i n}=140 \mathrm{~W}, \Delta t=18 \mathrm{~ms}\right),($ a) hydrodynamic behavior at $0 \mathrm{~ms}$; (b) $18 \mathrm{~ms}$; (c) $36 \mathrm{~ms}$; (d) $54 \mathrm{~ms}$.

Some typical images of the gas-liquid two-phase hydrodynamic behavior in the cavity of the PGHP at the working fluid filling ratio of $48 \%$ are shown in Figure 22. When the working fluid filling ratio of PGHP is high, the liquid level of the working fluid is close to the top of the condensation section and the disturbance of boiling fluid in the PGPH is relatively intense. It means that the interaction between evaporation, boiling heat transfer and condensation heat transfer is gradually increased. The bubbles carry boiling liquid to move upwards, and the condensation liquid shown in the yellow line on the condensation surface falls downwards under gravity. As time goes on, boiling liquid contacts with condensation liquid and scours the condensation surface, so that the condensation liquid on the wall is mixed with boiling liquid. The returning of condensate is affected by gravity and the scouring of the boiling fluid, which reduces the thickness of the condensation film and promotes condensation heat transfer. But if the working fluid filling ratio is too high, more resistance can be generated in the process of the rise of bubbles under certain heating conditions. Therefore, the rising speed of the bubble and the boiling heat transfer of the heat pipe are limited to some extent. The condensation section of the PGHP is covered with the boiling liquid for a long time, which causes a reduction in the heat transfer area of the steam and further affects the heat transfer process of the heat pipe. Therefore, a best working fluid filling ratio during the experiment can be obtained to reach the optimum heat transfer performance.

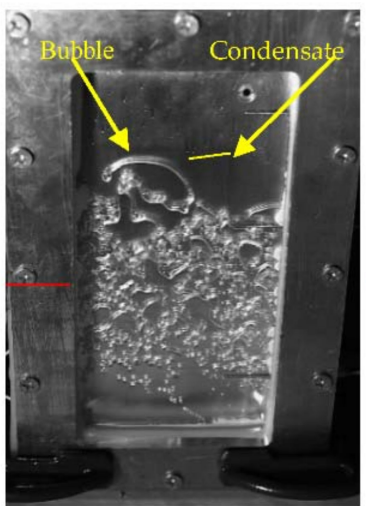

(a)

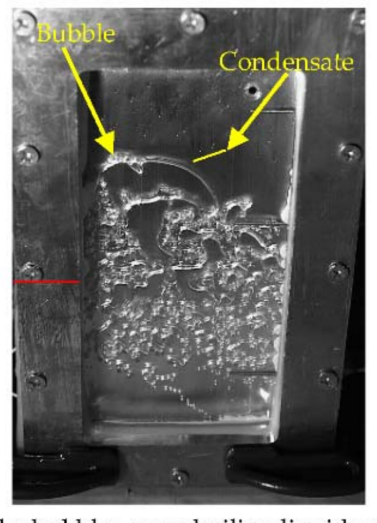

The bubbles carry boiling liquid up

(b)

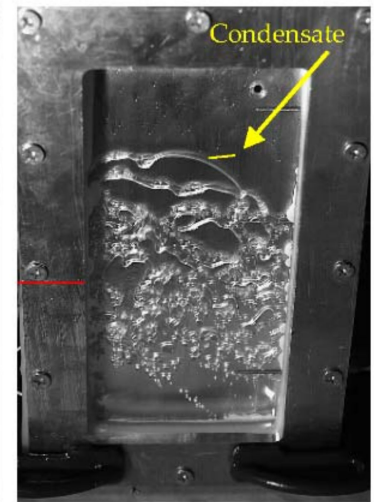

Boiling liquid contacts with condensate

(c)

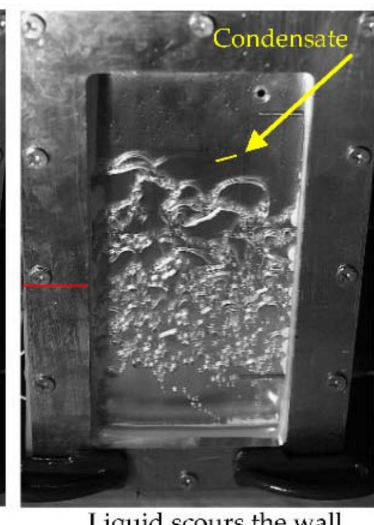

Liquid scours the wall

(d)

Figure 22. Typical images of gas-liquid two-phase hydrodynamic behavior in the cavity of PGHP (FR $=48 \%, Q_{\text {in }}=140 \mathrm{~W}, \Delta t=35 \mathrm{~ms}$ ). Note: the initial level is shown as the red line, (a) hydrodynamic behavior at $0 \mathrm{~ms}$; (b) $35 \mathrm{~ms}$; (c) $70 \mathrm{~ms}$; (d) $105 \mathrm{~ms}$. 


\section{Conclusions}

In this paper, a novel semi visualized plate gravity heat pipe was manufactured to study the effects of different heating power inputs and fluid filling ratios on the start-up temperature, start-up time, temperature difference and relative thermal resistance on the Z-axis of the PGHP at $1 \times 10^{-3} \mathrm{~Pa}$. Furthermore, the gas-liquid two-phase behavior of the interior working fluid of PGHP, the coupling heat transfer behavior of the boiling liquid and the condensate were observed simultaneously through a visualizable window under different experimental conditions. The findings can be concluded as follows:

(1) The start-up time of the PGHP decreases through enhancing the heating power input, whereas it accelerates with the increase of working fluid filling ratio. On the other hand, the start-up temperature of the PGHP rises with the increase of heating power input.

(2) With the heating power input increasing, the temperature difference on Z-axis of PGHP widens. The relative thermal resistance during the start-up process of PGHP increases and then drops as it is heated.

(3) Through analyzing the images in the experiment process, some complex gas-liquid two-phase hydrodynamic behaviors were observed in the operation process of PGHP, which mainly include the growth of bubbles, the merging of bubbles, the breakup of bubbles and the generation of condensate on the condensation wall.

(4) With the increase of heating power input, the disturbance of the working fluid in PGHP strengthens and the number of bubbles increases. Thus, the boiling heat transfer of the working fluid in PGHP enhances, which is beneficial to the heat exchange of the PGHP. Meanwhile, the condensate on the condensation surface of PGHP will be more obvious with the increase of heating power input, and the condensate flows downwards under gravity.

(5) A relatively independent relation exists between the boiling fluid and the condensate in PGHP at a lower working fluid filling ratio. However, if the working fluid filling ratio is too high, the boiling liquid inside the PGHP is covered on the condensation surface for a long time. As a result, the condensing area of the steam is reduced and the resistance increases, which also limits the boiling and condensation heat transfer of the PGHP. Therefore, a proper working fluid filling ratio can be obtained for efficient heat transfer.

Acknowledgments: This work was financially supported by the Hebei Applied Basic Research Program of China (Grant No. 13964503D).

Author Contributions: Xiang Gou conceived the research. Xiang Gou and Yamei Li designed the experiment. Yamei Li, Qiyan Zhang, Dong Zhao, Shian Liu, Yating Wang and Xiang Gou carried out the experiment. Xiang Gou, Yamei Li, Qiyan Zhang and Imran Ali Shah participated in the analysis of the data and writing the initial manuscript. Xiang Gou, Imran Ali Shah, Enyu Wang and Jinxiang Wu revised the manuscript and adjusted the data presentation. All authors have read and approved the manuscript.

Conflicts of Interest: The authors declare no conflict of interest.

\section{Abbreviations}

The following abbreviations are used in this manuscript:

$\begin{array}{ll}C_{p} & \text { specific heat at constant pressure of air, }\left(\mathrm{J} / \mathrm{kg} \cdot{ }^{\circ} \mathrm{C}\right) \\ \text { FR } & \text { working fluid filling ratio, }(\%) \\ \text { NHSP } & \text { novel hybrid-structure flat plate heat pipe } \\ P_{\text {cap }} & \text { capillary pressure, }(\mathrm{Pa}) \\ P_{\text {sat }} & \text { saturation pressure, }(\mathrm{Pa}) \\ \text { PGHP } & \text { plate gravity heat pipe } \\ Q_{a c} & \text { actual heat transfer, }(\mathrm{W}) \\ Q_{i n} & \text { input power of evaporation section, }(\mathrm{W}) \\ R & \text { relative thermal resistance, }(\mathrm{K} / \mathrm{W}) \\ \text { SVPGHP } & \text { semi visualized plate gravity heat pipe }\end{array}$


$T_{\mathcal{C}} \quad$ average temperature of condensation section, $\left({ }^{\circ} \mathrm{C}\right)$

$T_{e} \quad$ average temperature of evaporation section, $\left({ }^{\circ} \mathrm{C}\right)$

$T_{i} \quad$ air inlet temperature, $\left({ }^{\circ} \mathrm{C}\right)$

$T_{0} \quad$ air outlet temperature, $\left({ }^{\circ} \mathrm{C}\right)$

$T_{\text {st }} \quad$ start-up temperature, $\left({ }^{\circ} \mathrm{C}\right)$

$t_{s t} \quad$ start-up time, (s)

$V \quad$ volumetric flow of air, $\left(\mathrm{m}^{3} / \mathrm{s}\right)$

VD vacuum degree, $(\mathrm{Pa})$

$\Delta T \quad$ temperature difference, $\left({ }^{\circ} \mathrm{C}\right)$

$\Delta t \quad$ time interval, (ms)

$\rho \quad$ the density of air, $\left(\mathrm{kg} / \mathrm{m}^{3}\right)$

Subscript

c condensation

e evaporation

cap capillary

i inlet

o outlet

$\mathrm{p} \quad$ pressure

sat saturation

st start-up

\section{References}

1. North, M.T.; Avedisian, C.T. Heat pipes for cooling high flux/high power semiconductor chips. J. Electron. Pack. Trans. 1993, 115, 112-117. [CrossRef]

2. Oshman, C.; Shi, B.; Li, C.; Yang, R.; Lee, Y.; Peterson, G. The development of polymer-based flat heat pipes. J. Microelectromec. Syst. 2011, 20, 410-417. [CrossRef]

3. Chen, J.S.; Chou, J.H. The length and bending angle effects on the cooling performance of flat plate heat pipes. Int. J. Heat Mass Transf. 2015, 90, 848-856. [CrossRef]

4. Vasiliev, L.L. Micro and miniature heat pipes-electronic component coolers. Appl. Therm. Eng. 2008, 28, $266-273$. [CrossRef]

5. McGlen, R.J.; Jachuck, R.; Lin, S. Integrated thermal management techniques for high power electronic devices. Appl. Therm. Eng. 2004, 24, 1143-1156. [CrossRef]

6. Ju, Y.S.; Kaviany, M.; Nam, Y.; Sharratt, S.; Hwang, G.S.; Catton, I.; Fleming, E.; Dussinger, P. Planar vapor chamber with hybrid evaporator wicks for the thermal management of high-heat-flux and high-power optoelectronic devices. Int. J. Heat Mass Transf. 2013, 60, 163-169. [CrossRef]

7. Elnaggar, M.H.A.; Abdullah, M.Z.; Mujeebu, M.A. Experimental analysis and FEM simulation of finned U-shape multi heat pipe for desktop PC cooling. Energy Convers. Manag. 2011, 52, 2937-2944. [CrossRef]

8. Elnaggar, M.H.A.; Abdullah, M.Z.; Mujeebu, M.A. Characterization of working fluid in vertically mounted finned U-shape twin heat pipe for electronic cooling. Energy Convers. Manag. 2012, 62, 31-39. [CrossRef]

9. Rao, Z.H.; Wang, S.F.; Wu, M.H.; Lin, Z.R.; Li, F.H. Experimental investigation on thermal management of electric vehicle battery with heat pipe. Energy Convers. Manag. 2013, 65, 92-97. [CrossRef]

10. Koito, Y.; Motomatsu, K.; Imura, H.; Mochizuki, M.; Saito, Y. Fundamental investigations on heat transfer characteristics of heat sinks with a vapor chamber. In Proceedings of the 7th International Heat Pipe Symposium, Jeju, Korea, 12-16 October 2003; Volume 11, pp. 247-251.

11. Koito, Y.; Imura, H.; Mochizuki, M.; Saito, Y.; Torii, S. Numerical analysis and experimental verification on thermal fluid phenomena in vapour chamber. Appl. Therm. Eng. 2006, 26, 1669-1676. [CrossRef]

12. Hansen, G.; Næss, E.; Kristjansson, K. Analysis of a Vertical Flat Heat Pipe Using Potassium Working Fluid and a Wick of Compressed Nickel Foam. Energies 2016, 9, 170. [CrossRef]

13. Kim, H.J.; Lee, S.H.; Kim, S.B.; Jang, S.K. The effect of nanoparticle shape on the thermal resistance of a flat-plate heat pipe using acetone-based $\mathrm{Al}_{2} \mathrm{O}_{3}$ nanofluids. Int. J. Heat Mass Transf. 2016, 92, 572-577. [CrossRef]

14. Hari, R.; Jolly, T.; Muraleedharan, C. Numerical investigation of deviation of phase change characteristics of horizontal and vertical flat heat pipe configurations. J. Comput. Multiph. Flow 2015, 7, 259-270. [CrossRef] 
15. Huang, H.J.; Shen, S.C.; Shaw, H.J. Design and Fabrication of a Novel Hybrid-Structure Heat Pipe for a Concentrator Photovoltaic. Energies 2012, 5, 4340-4349. [CrossRef]

16. Peng, H.; Li, J.; Ling, X. Study on heat transfer performance of an aluminum flat plate heat pipe with fins in vapor chamber. Energy Convers. Manag. 2013, 74, 44-50. [CrossRef]

17. Tan, B.K.; Wong, T.N.; Ooi, K.T. Analytical effective length study of a flat plate heat pipe using point source approach. Appl. Therm. Eng. 2005, 25, 2272-2284. [CrossRef]

18. Ji, X.; Li, H.; Xu, J.; Huang, Y. Integrated flat heat pipe with a porous network wick for high-heat-flux electronic devices. Exp. Therm. Fluid Sci. 2017, 85, 119-131. [CrossRef]

19. Hansen, G.; Næss, E.; Kristjansson, K. Sintered Nickel Powder Wicks for Flat Vertical Heat Pipes. Energies 2015, 8, 2337-2357. [CrossRef]

20. Halon, T.; Zajaczkowski, B.; Michaie, S.; Rulliere, R.; Bonjour, J. Experimental study of low pressure pool boiling of water from narrow tunnel surfaces. Int. J. Therm. Sci. 2017, 121, 348-357. [CrossRef]

21. Michaie, S.; Rullière, R.; Bonjour, J. Experimental study of bubble dynamics of isolated bubbles in water pool boiling at subatmospheric pressures. Exp. Therm. Fluid Sci. 2017, 87, 117-128. [CrossRef]

22. Deng, D.; Wan, W.; Feng, J.; Huang, Q.; Qin, Y.; Xie, Y. Comparative experimental study on pool boiling performance of porous coating and solid structures with reentrant channels. App. Therm. Eng. 2016, 107, 420-430. [CrossRef]

23. Kaniowski, R.; Pastuszko, R. Pool boiling visualization on open microchannel surfaces. EPJ Web Conf. 2017, 143. [CrossRef]

24. Falcucci, G.; Ubertini, S.; Bella, G.; Succi, S. Lattice Boltzmann Simulation of Cavitating Flows. Commun. Comput. Phys. 2013, 13, 685-695. [CrossRef]

25. Falcucci, G.; Jannelli, E.; Ubertini, S.; Succi, S. Direct numerical evidence of stress-induced cavitation. J. Fluid Mech. 2013, 728, 362-375. [CrossRef]

26. Falcucci, G. Direct Numerical Simulation of Flow Induced Cavitation in Orifices. Int. J. Fuels Lubr. 2013, 6, 915-921. [CrossRef]

27. Falcucci, G.; Ubertini, S.; Succi, S. Lattice Boltzmann simulations of phase-separating flows at large density ratios: The case of doubly-attractive pseudo-potentials. Soft Matter 2010, 6, 4357-4365. [CrossRef]

28. De Rosis, A.; Falcucci, G.; Ubertini, S.; Ubertini, F. A coupled lattice Boltzmann-finite element approach for two-dimensional fluid-structure interaction. Comput. Fluids 2013, 86, 558-568. [CrossRef]

29. De Rosis, A.; Falcucci, G.; Porfiri, M.; Ubertini, F.; Ubertini, S. Hydroelastic analysis of hull slamming coupling lattice Boltzmann and finite element methods. Comput. Struct. 2014, 138, 24-35. [CrossRef]

30. Xue, Z.H.; Chen, S.Y.; Wei, Q.U. The visualized startup and thermal performance of ammonia pulsating heat pipe. J. Sci. Sin. 2015, 45, 999-1006.

31. Xue, Z.H.; Qu, W.; Xie, M.H. Full visualization and startup performance of an ammonia pulsating heat pipe. Propuls. Power 2013, 2, 263-268. [CrossRef]

32. Xue, Z.H.; Qu, W. Experimental and theoretical research on an ammonia pulsating heat pipe: New full visualization of flow pattern and operating mechanism study. Int. J. Heat Mass Transf. 2017, 106, 149-166. [CrossRef]

33. Goshayeshi, H.R.; Chaer, I. Experimental study and flow visualization of $\mathrm{Fe}_{2} \mathrm{O}_{3} /$ kerosene in glass oscillating heat pipes. Appl. Therm. Eng. 2016, 103, 1213-1218. [CrossRef]

34. Qu, J.; Wu, H.; Heng, P. Start-up, heat transfer and flow characteristics of silicon-based micro pulsating heat pipes. Int. J. Heat Mass Transf. 2012, 55, 6109-6120. [CrossRef]

35. Wilson, C.; Borgmeyer, B.; Winholtz, R.A.; Ma, H.B.; Jacobson, D.; Hussey, D. Thermal and Visual Observation of Water and Acetone Oscillating Heat Pipes. J. Heat Transf. 2011, 133, 381-386. [CrossRef]

36. Xu, J.L.; Li, Y.X.; Wong, T.N. High speed flow visualization of a closed loop pulsating heat pipe. Int. J. Heat Mass Transf. 2005, 48, 3338-3351. [CrossRef]

37. Putra, N.; Ramadhan, R.S.; Septiadi, W.N.; Sutiarso. Visualization of the boiling phenomenon inside a heat pipe using neutron radiography. Exp. Therm. Fluid Sci. 2015, 66, 13-27. [CrossRef]

(C) 2017 by the authors. Licensee MDPI, Basel, Switzerland. This article is an open access article distributed under the terms and conditions of the Creative Commons Attribution (CC BY) license (http://creativecommons.org/licenses/by/4.0/). 